\title{
Maximizing Versus Satisficing: Happiness Is a Matter of Choice
}

\author{
Barry Schwartz and Andrew Ward \\ Swarthmore College
}

Sonja Lyubomirsky

University of California, Riverside

\author{
John Monterosso \\ University of Pennsylvania
}

\begin{abstract}
Can people feel worse off as the options they face increase? The present studies suggest that some people-maximizers_can. Study 1 reported a Maximization Scale, which measures individual differences in desire to maximize. Seven samples revealed negative correlations between maximization and happiness, optimism, self-esteem, and life satisfaction, and positive correlations between maximization and depression, perfectionism, and regret. Study 2 found maximizers less satisfied than nonmaximizers (satisficers) with consumer decisions, and more likely to engage in social comparison. Study 3 found maximizers more adversely affected by upward social comparison. Study 4 found maximizers more sensitive to regret and less satisfied in an ultimatum bargaining game. The interaction between maximizing and choice is discussed in terms of regret, adaptation, and self-blame.
\end{abstract}

Rational choice theory has tried to explain preference and choice by assuming that people are rational choosers (von Neumann \& Morgenstern, 1944). According to the rational choice framework, human beings have well-ordered preferences-preferences that are essentially impervious to variations in the way the alternatives they face are described or the way in which they are packaged or bundled. The idea is that people go through life with all their options arrayed before them, as if on a buffet table. They have complete information about the costs and benefits associated with each option. They compare the options with one another on a single scale of preference, or value, or utility. And after making the comparisons, people choose so as to maximize their preferences, or values, or utilities.

Although the science of economics has historically depended on the tenets of rational choice theory, it is now well established that many of the psychological assumptions underlying rational choice theory are unrealistic and that human beings routinely violate the

Barry Schwartz and Andrew Ward, Department of Psychology, Swarthmore College; John Monterosso, Department of Psychology, University of Pennsylvania; Sonja Lyubomirsky, Department of Psychology, University of California, Riverside; Katherine White and Darrin R. Lehman, Department of Psychology, University of British Columbia, Vancouver, British Columbia, Canada.

This research was facilitated by support from the Positive Psychology Network (M. Seligman, Director), an intramural grant from Swarthmore College to Barry Schwartz, a sabbatical grant from the Solomon Asch Center for Study of Ethnopolitical Conflict to Andrew Ward, an intramural grant from the University of California to Sonja Lyubomirsky, a Social Sciences and Humanities Research Council (SSHRC) doctoral fellowship to Katherine White, and grants from SSHRC and the Natural Sciences and Engineering Research Council to Darrin R. Lehman.

Correspondence concerning this article should be addressed to Barry Schwartz, Department of Psychology, Swarthmore College, 500 College Avenue, Swarthmore, Pennsylvania 19081. E-mail: bschwar1@ swarthmore.edu principles of rational choice (e.g., J. Baron, 2000; Kahneman \& Tversky, 1979, 1984; Tversky, 1969; Tversky \& Kahneman, 1981; for a discussion, see Schwartz, 1986, 1994). In particular, modern behavioral economics has acknowledged that the assumption of complete information that characterizes rational choice theory is implausible. Rather than assuming that people possess all the relevant information for making choices, choice theorists treat information itself as a "commodity," something that has a price (in time or money), and is thus a candidate for consumption along with more traditional goods (e.g., Payne, 1982; Payne, Bettman, \& Johnson, 1993).

Almost a half century ago, Simon $(1955,1956,1957)$ suggested an approach to explaining choice that was more cognizant of human cognitive limitations than rational choice theory. Simon argued that the presumed goal of maximization (or optimization) is virtually always unrealizable in real life, owing both to the complexity of the human environment and the limitations of human information processing. He suggested that in choice situations, people actually have the goal of "satisficing" rather than maximizing. To satisfice, people need only to be able to place goods on some scale in terms of the degree of satisfaction they will afford, and to have a threshold of acceptability. A satisficer simply encounters and evaluates goods until one is encountered that exceeds the acceptability threshold. That good is chosen. In subsequent, accidental encounters with other goods in the relevant domain, the scale of acceptability enables one to reject a formerly chosen good for a higher ranked one should that one turn up. A satisficer thus often moves in the direction of maximization without ever having it as a deliberate goal. Simon's alternative to rational choice theory questions not only the processes by which options are assessed and choices made, but also the motives that underlie choice. To satisfice is to pursue not the best option, but a good enough option.

\section{Can There Be Too Much Choice?}

There is no question that greater choice can provide benefits for the chooser. Indeed it is axiomatic in rational choice theory that 
people cannot have too many options. If, for example, one is trying to decide between two models of a CD player, and then discovers that a third model also is available, the third model may be just the thing one is after. If not, one can simply go back to deliberating between the first two. And one can always ignore the new, third option altogether. So it seems irrational to perceive oneself as worse off as a result of added possibilities for choice. Nonetheless, there is now a small body of evidence suggesting that added options are a mixed blessing (e.g., Simenson \& Tversky, 1992; Tversky \& Shafir, 1992). Results have begun to appear in the decision-making literature indicating that adding options can make a choice situation less rather than more attractive for people - that indeed, sometimes people prefer it if others make the choices for them (Beattie, Baron, Hershey, \& Spranca, 1994).

In one series of studies (Iyengar \& Lepper, 2000; see also Iyengar \& Lepper, 1999), participants were more likely to purchase exotic jams or gourmet chocolates when they had 6 options from which to choose than when they had 24 or 30 , respectively. And perhaps more importantly, those with fewer options expressed greater satisfaction with the choices they made. Similarly, university students were more likely to write an extracredit essay, and wrote better essays, when they had 6 topics to choose from than when they had 30. Iyengar and Lepper suggested several possible factors that may underlie this effect. One is the avoidance of potential regret. The more options there are, the more likely one will make a nonoptimal choice, and this prospect may undermine whatever pleasure one gets from one's actual choice. There is ample evidence that regret aversion is a potent force in decision making-perhaps even more potent than the loss aversion that has been a significant feature of Kahneman and Tversky's (1979) prospect theory of decision making (Beattie et al., 1994; Bell, 1982, 1985; Larrick \& Boles, 1995; Loomes \& Sugden, 1982; Ritov, 1996; Simenson, 1992; Zeelenberg, 1999; Zeelenberg \& Beattie, 1997; Zeelenberg, Beattie, van der Pligt, \& de Vries, 1996; Zeelenberg et al., 1998).

A second factor that may make increased choice unattractive is that it creates a seemingly intractable information problem. It is hard enough to gather information and go through the deliberations needed to make the best choice among 6 options. To choose the best among 30 options is truly daunting. So rather than even try, people may disengage, choosing almost arbitrarily to complete the process. As a result of this disengagement, many of the psychological processes that normally are recruited to enhance the attractiveness of the choices one makes may not be operative (see Gilovich \& Medvec, 1995, for an account of some of these processes, in the context of their theory of regret).

\section{Maximizing, Satisficing, and Choice}

Schwartz (2000) recently argued that the proliferation of options can have a variety of negative effects on well-being. He suggested that as options are added within a domain of choice, three problems materialize. First, there is the problem of gaining adequate information about the options to make a choice. Second, there is the problem that as options expand, people's standards for what is an acceptable outcome rise. And third, there is the problem that as options expand, people may come to believe that any unacceptable result is their fault, because with so many options, they should be able to find a satisfactory one. Similar problems arise as choice becomes available in domains in which previously there was no choice. No matter how dissatisfied one is with one's telephone service, if phone service is provided by a regulated monopoly, one cannot do better, and inadequate service is not one's fault. However, when choice of phone service becomes available, there is no longer any reason to tolerate inadequate service, and failure to obtain adequate service is one's responsibility. Schwartz (2000) suggested that people might in general be better off with constrained and limited choice than with unconstrained choice.

However, expanded opportunities for choice need not have these negative psychological effects. Consider the different effects that an expanding array of options might have on two people, one of whom aims to maximize his or her outcomes in that domain and one of whom aims to satisfice. For the maximizer, added options pose problems. One cannot be sure that one is making the maximizing choice without examining all the alternatives. And if it is impossible or impractical to examine all the alternatives, then when the maximizer gives up the search and chooses, there will be a lingering doubt that he or she could have done better by searching a bit more. Thus, as options proliferate, the likelihood of achieving the goal of maximization goes down. Further, the potential for regret is ever present, because the question the maximizer is asking him- or herself is not "is this a good outcome?" but "is this the best outcome?".

Expanded opportunities for choice may have different effects on the satisficer. The satisficer is looking for something that crosses the threshold of acceptability-something that is good enough. Adding options in a domain in which the satisficer has already encountered something good enough need have no effect; the new options may simply be ignored. With "good enough" rather than the "best" as a criterion, the satisficer will be less inclined to experience regret if it turns out that an option better than the chosen one was available. And if no satisfactory option has been encountered in a domain, added options will provide new possibilities for finding something that crosses the "good enough" threshold. Thus, the risk of being made worse off by added options may be minimal for satisficers.

Are some people maximizers and others satisficers? Do people differ in the nature of the goals they pursue in choice situations? And if so, do people also differ in their sensitivity to potential regret? Is it concern about potential regret that influences some people to be maximizers? We addressed these questions in the present series of studies by creating survey instruments designed to distinguish maximizers from satisficers and to measure sensitivity to regret. And if people do differ in these respects, does it make a difference? We addressed this question in the present studies in several ways. Study 1 examined the relations between one's scores on a Maximization Scale and a Regret Scale and scores on measures of happiness, life satisfaction, optimism, depression, neuroticism, and perfectionism. In subsequent studies we attempted to validate some of these putative relations and to identify possible mediators. Study 2, guided by the notion that maximizers might seek more information than satisficers when making decisions, used a questionnaire to examine relations between maximization and the amount of social comparison that goes into making purchasing decisions, as well as the satisfaction people derive from those decisions. Study 3, inspired by findings reported by Lyubomirsky and Ross (1997) that unhappy people are more affected by upward social comparison than happy people, further explored 
the relation between maximizing and social comparison processes by examining whether maximizers and satisficers respond differentially to social comparison manipulations. Finally, Study 4 examined the possible causal role of regret in mediating between maximizing and dissatisfaction by exposing participants to a computer game designed to manipulate the potential for regret. We anticipated that maximizers would be more sensitive to regret than satisficers, and would derive less satisfaction from their results in games in which the opportunity for regret was salient.

\section{Study 1. Maximizing, Satisficing, and Regret: Scale Development}

This study involved the creation and evaluation of two new measuring instruments - one designed to assess the tendency to satisfice or maximize and one designed to assess the tendency to experience regret. Materials were administered to seven samples of participants, four of them university students and three of them community adults. In total, 1,747 participants completed the maximizing and regret questionnaires.

\section{Method}

\section{Overview}

Packets of questionnaires were administered to seven samples (total $N=1,747)$. Participants completed the questionnaires either in small groups of 3 to 7 (Samples 1 and 3), during one large, group session (Samples 2, 4, 5, and 7), or individually (Sample 6). Completing the questionnaires required less than $45 \mathrm{~min}$ (in the case of Sample 6, less than $15 \mathrm{~min}$ ). For each administration, the content of the questionnaires varied, as described below.

\section{Participants}

Each of the first four samples comprised students in introductory psychology courses, who received course credit for their participation. The first two samples $(n=82$ and $n=72)$ were recruited at Swarthmore College, the third sample $(n=100)$ at the University of California, Riverside, and the fourth sample $(n=401)$ at the University of British Columbia, Vancouver, Canada. The fifth sample $(n=752)$ consisted of participants at a 1-day seminar for allied health care professionals (mean age $=47$ years), the majority of whom were nurses. The sixth sample $(n=$ 220) was composed of individuals recruited at a large train station in an urban setting (mean age $=41$ years), and the seventh $(n=120)$ comprised individuals in an urban courthouse approached while waiting to be informed if they would serve on a jury (mean age $=40$ years). There were approximately equal numbers of males and females in the first three samples, along with the sixth sample (i.e., individuals at the train station), but the fourth sample (i.e., students at the University of British Columbia) included 258 females and 141 males (2 participants failed to identify their gender), the fifth sample (i.e., health care providers) included 684 females and 60 males ( 8 participants failed to identify their gender), and the final sample (members of a jury pool) included 87 females, 28 males, and 5 individuals who failed to identify their gender. The third, fourth, and seventh samples also were quite diverse ethnically. The third sample was 39\% Asian, 24\% Caucasian, 10\% Chicano(a)/Latino(a), 8\% African American, and $10 \%$ other, and the fourth sample (classified using slightly different categories) was $51 \%$ of East Asian descent (e.g., Chinese, Taiwanese), 25\% of Western European descent (e.g., British, French), 9\% of East Indian descent (e.g., Indian, Pakistani), and 15\% other. The seventh sample was 48\% Caucasian, 45\% African American, and 7\% other.

\section{Materials}

Sample 1. Our aim with the first sample was to create maximization and regret scales and to investigate correlations between responses to those scales and well-established measures of well-being. Participants completed a preliminary 42-item questionnaire designed to measure maximization (33 items) and regret (9 items). Participants responded to each item using a 7-point, Likert-type scale $(1=$ completely disagree, $7=$ completely agree). In addition, they completed a four-item Subjective Happiness Scale (SHS) designed to assess dispositional happiness (Lyubomirsky \& Lepper, 1999), a depression survey (the 13-item short form of the Beck Depression Inventory [BDI-SF; Beck \& Beck, 1972]), and a measure of dispositional optimism (the Life Orientation Test [LOT; Scheier \& Carver, 1985]).

On the basis of item reliability and face validity, the measure was reduced to 22 items, 17 assessing maximization and 5 assessing regret. These 22 items were then presented to 11 judges (advanced undergraduate students majoring either in psychology or economics) who were unaware of either the purpose of our studies or the specific hypotheses under investigation. The judges were asked to examine each item and indicate whether, on the one hand, it probed an individual's inclination to "get the best out of any situation" or "settle for good enough," or, on the other hand, it probed a person's sensitivity to "the possibility that he or she might regret a decision once made." Of the 5 "regret" items, 4 were judged by 10 of our 11 informants to be about regret and the 5th was judged by 9 informants to be about regret. Of the 17 "maximization" items, 10 were judged by 10 of 11 informants to be about maximization, 3 were so judged by 9 informants, and 4 were so judged by 7 informants. Thus, we were reasonably confident that our measures had face validity - that our understanding of what the questions were asking would be matched by that of the participants. We then submitted the 5 regret items and 17 maximization items to a principal-components factor analysis (PCA), which is reported below.

Sample 2. Participants in the second sample received these 22 items, unidentified and intermixed. In an independent test of the putative associations investigated in Sample 1, they were also asked to complete the SHS and the BDI-SF.

Sample 3. Participants in the third sample completed the same 22-item questionnaire assessing maximization and regret, along with the SHS, BDI-SF, and LOT. In addition, they completed a questionnaire probing life satisfaction (the Satisfaction With Life Scale [Diener, Emmons, Larsen, \& Griffin, 1985]) and a scale assessing dispositional Neuroticism (John, Donahue, \& Kentle, 1991), a Big Five trait that we thought might be correlated with maximization.

Sample 4. The fourth sample of participants completed the 22-item questionnaire along with the SHS. In addition, these participants were asked a series of questions regarding tendencies to engage in social comparison and patterns of purchasing behavior. These materials comprise the substance of Study 2 and thus discussion of them appears later in the article.

Sample 5. The fifth sample completed the same 22-item questionnaire in addition to the aforementioned measures of happiness and depression (i.e., the SHS and BDI).

Sample 6. The sixth sample also completed the 22-item questionnaire and the SHS, along with a 15-item perfectionism subscale composed of the Self-Oriented Perfectionism items of the Multidimensional Perfectionism Scale (Hewitt \& Flett, 1990, 1991). The addition of this scale was intended to investigate participants' tendencies to hold exceedingly high standards for themselves in a variety of domains. The scale included items such as, "One of my goals is to be perfect in everything I do," and "I demand nothing less than perfection of myself" ( $1=$ disagree, $7=$ agree $)$. In addition, a subset of participants $(n=146)$ completed the 10 -item measure of self-esteem developed by Rosenberg (1965).

Sample 7. The only measures relevant to this article that were completed by members of the prospective jury pool were the 22 -item maximi- 
zation/regret survey and the same 10-item measure of self-esteem (Rosenberg, 1965).

\section{Results}

\section{Factor Analysis}

We conducted a PCA on the combined samples $(n=1,747)$ to determine the factor structure of the regret and maximizing items. We sought the solution that best approximated a simple structure - that is, the one in which most of the items loaded on at least one factor, and each item loaded on only one factor. What emerged, on the basis of a varimax rotation, was a six-factor solution. However, two of the factors contained only two items each, and one item failed to load on any of the factors. In addition, the item-total correlations for all but one of these five items were quite low. We thus eliminated the four items with low item-total correlations, resulting in a 13-item Maximization Scale and a five-item Regret Scale. We conducted another PCA on these 18 items. The resulting four-factor solution is presented in Table 1 . The first factor, on which all five regret items loaded, references "regret," and makes up the Regret Scale. The other factors are subcategories of maximizing/satisficing and make up the Maximization Scale. The second and third factors are largely behavioral examples of maximizing. The second factor includes being open to better jobs, songs on the radio, television shows, and relationships, liking lists that rank things, and fantasizing about alternatives to reality (which also loaded on the "regret" factor, though its loading was lower than that of the other "regret" items; in addition, this item was judged by 9 of our 11 informants to be more about maximizing and satisficing than about regret). The third factor, which concerns primarily shopping behaviors, includes shopping for a friend, renting videos, and shopping for clothing. Writing several drafts of letters so as to word things just right also loads on this factor. The fourth factor represents having high standards, both for oneself and for things in general. One of the items that loaded on this factor also loaded on the "regret" factor. Its loading on the "regret" factor was substantially lower than all the other regret items, and also lower than its loading on this "maximizing" factor. Moreover, this item was judged by 10 of our 11 informants to be about maximizing. All further analyses, in this and subsequent studies, used responses to the modified, 13-item Maximization Scale rather than the 17-item scale participants actually saw. The correlation (across all participants) between scores on the 13and the 17-item scales was $.99(p<.001)$. Cronbach's alpha was .71 for the Maximization Scale and .67 for the Regret Scale.

\section{Correlations With Standard Personality Measures}

Sample 1. Table 2 presents the Pearson's zero-order correlations between the variables investigated in Study 1. As can be seen in the table, a tendency for participants to be maximizers rather than satisficers $(\alpha=.70)$ was significantly correlated with a tendency to experience more regret and depression, as well as to be less optimistic, and less happy $(p<.06)$. By way of further illustration, of the 18 people who scored 8 or above on the BDI-SF, qualifying for a diagnosis of at least mild depressive symptoms (Beck \& Beck, 1972), 8 (44\%; Mean BDI score $=13.25)$ also scored in the top quartile for maximization, whereas only $1(6 \%$; BDI score $=8$ ) scored in the bottom quartile. By contrast, of the 19 people scoring in the top quartile for happiness, 8 (42\%; Mean SHS score $=16.88$ ) were in the bottom quartile for maximization, whereas only $3(16 \%$; Mean SHS score $=16.33)$ were in the top quartile.

Sample 2. Table 2 also presents the correlations between the 13-item maximization composite $(\alpha=.60)$ and the five-item regret composite $(\alpha=.78)$ for Sample 2, along with the BDI-SF and the SHS - the only other measures administered to this sample. Once again, we observed strong associations between maximization and a tendency to experience regret and depression, and lower levels of happiness.

Sample 3. Our third sample provided a further opportunity to investigate relations between maximization and various personality constructs. Table 2 presents the intercorrelations between the maximization composite $(\alpha=.70)$, the regret composite $(\alpha=$ .70 ), and measures of optimism, happiness, depression, neuroticism, and satisfaction with life. Correlations between maximizing and the constructs of regret, depression, and satisfaction with life were significant beyond the $p<.01$ range. In addition, maximizing was negatively correlated with optimism $(p<.05)$ and happiness $(p<.10)$. However, the relation between maximizing and neuroticism was not significant $(p>.10)$. In sum, in addition to replicating the results found with Sample 1, this sample provided evidence for a strong relation between maximization and diminished life satisfaction, as well as a nonsignificant relation with neuroticism.

Sample 4. Table 2 presents data from our fourth sample on the relations between the maximization composite $(\alpha=.63)$, the regret composite ( $\alpha=.73)$, and the SHS. Once again, the correlation between maximizing and regret was significant, although the relation between maximizing and happiness was modest $(r=.10$, $p<.05)$.

Sample 5. The fifth section of Table 2 displays the correlations between maximizing ( $\alpha=.70)$, regret ( $\alpha=.74$ ), happiness, and depression for the sample of health care providers who completed the relevant measures. As seen with the previous samples, a tendency to score highly on the Maximization Scale was predictive of greater regret and depression, as well as lower levels of selfreported happiness.

Sample 6. The sixth section of Table 2 presents correlations for participants approached at the urban train station. Once again, maximizing ( $\alpha=.72)$ was positively correlated with regret $(\alpha=$ $.67)$, and negatively correlated with happiness. In addition, maximizing was significantly correlated with perfectionism $(r=.25$, $p<.001)$. And for the subsample who completed the relevant measure, maximizing and self-esteem were negatively correlated $(r=-.30, p<.001)$. Interestingly, however, whereas maximizing and perfectionism were significantly correlated, neither happiness $(r=.12, p<.08)$ nor self-esteem $(r=.02, n s)$ correlated significantly with perfectionism. Indeed, if anything, the relation between perfectionism and happiness was positive rather than negative.

Sample 7. The final sample, taken from prospective jury members, replicated the significant association between maximizing $(\alpha=.73)$ and self-esteem exhibited by the subsample in Sample 6, $(r=-.26, p<.01)$.

Across the seven samples, maximization scores ranged from 1.15 to 6.62 , with a mean of 3.88 and a median of 3.85. Also, across all samples, the correlation between maximizing and regret 
Table 1

Factor Analysis of the Regret and Maximization Scales Using PCA With Varimax Rotation

\begin{tabular}{c} 
Factor \\
\hline Regret Scale
\end{tabular}

happened if I had chosen differently.

F1 $\quad$ F2 $\quad$ F3 $\quad$ F4 $\quad$ Item-total $r$

Whenever I make a choice, I try to get information about how the other alternatives turned out.

If I make a choice and it turns out well, I still feel like something of a failure if I find out that another choice would have turned out better.

When I think about how I'm doing in life, I often assess opportunities I have passed up.

Once I make a decision, I don't look back. (R)

Maximization Scale

When I watch TV, I channel surf, often scanning through the available options even while attempting to watch one program.

When I am in the car listening to the radio, I often check other stations to see if something better is playing, even if I'm relatively satisfied with what I'm listening to.

I treat relationships like clothing: I expect to try a lot on before I get the perfect fit.

No matter how satisfied I am with my job, it's only right for me to be on the lookout for better opportunities.

I often fantasize about living in ways that are quite different from my actual life.

I'm a big fan of lists that attempt to rank things (the best movies, the best singers, the best athletes, the best novels, etc.).

I often find it difficult to shop for a gift for a friend.

When shopping, I have a hard time finding clothing that I really love.

Renting videos is really difficult. I'm always struggling to pick the best one.

I find that writing is very difficult, even if it's just writing a letter to a friend, because it's so hard to word things just right. I often do several drafts of even simple things.

No matter what I do, I have the highest standards for myself.

I never settle for second best.

Whenever I'm faced with a choice, I try to imagine what all the other possibilities are, even ones that aren't present at the moment.

Note. Item marked by "R" was reverse scored in the analysis. The factor analysis was a principal-components analysis (PCA) with varimax rotation, using eigenvalues greater than 1 as the extraction method. The last column displays the corrected item-total correlations for each item with its respective scale (i.e., regret [first five items] or maximization). 
Table 2

Pearson's Zero-Order Correlations Among Variables in Six Samples

\begin{tabular}{|c|c|c|c|c|c|c|}
\hline Variable & Max & Regret & SHS & BDI & LOT & NR \\
\hline \multicolumn{7}{|c|}{ Sample $1(n=82)$} \\
\hline Regret & $.61 * * *$ & & & & & - \\
\hline SHS & -.21 & -.15 & & & & - \\
\hline BDI & $.24 *$ & .03 & $-.46 * * *$ & & & - \\
\hline LOT & $-.28 *$ & -.07 & $.54 * * *$ & $-.51 * * *$ & & - \\
\hline \multicolumn{7}{|c|}{ Sample $2(n=72)$} \\
\hline Regret & $.45^{* * *}$ & & & & - & - \\
\hline SHS & $-.34 * *$ & $-.40 * *$ & & & - & - \\
\hline BDI & $.44 * * *$ & $.46^{* * *}$ & $-.55^{* * *}$ & & - & - \\
\hline \multicolumn{7}{|c|}{ Sample $3(n=100)$} \\
\hline Regret & $.36 * * *$ & & & & & \\
\hline SHS & -.17 & $-.51 * * *$ & & & & \\
\hline BDI & $.27 * *$ & $.47 * * *$ & $-.66^{* * *}$ & & & \\
\hline LOT & $-.25^{*}$ & $-.35 * * *$ & $.74 * * *$ & $-.54 * * *$ & & \\
\hline NR & .16 & $.35 * * *$ & $-.58 * * *$ & $.49 * * *$ & $-.50 * * *$ & \\
\hline SWLS & $-.27 * *$ & $-.54 * * *$ & $.71 * * *$ & $-.68 * * *$ & $.59 * * *$ & $-.48 * * *$ \\
\hline \multicolumn{7}{|c|}{ Sample $4(n=401)$} \\
\hline Regret & $.39 * * *$ & & & - & - & - \\
\hline SHS & $-.10 *$ & $-.27 * * *$ & & - & - & - \\
\hline \multicolumn{7}{|c|}{ Sample $5(n=752)$} \\
\hline Regret & $.46^{* * *}$ & & & & - & - \\
\hline SHS & $-.28 * * *$ & $-.40 * * *$ & & & - & - \\
\hline BDI & $.31 * * *$ & $.39 * * *$ & $-.66^{* * *}$ & & - & - \\
\hline \multicolumn{7}{|c|}{ Sample $6(n=220)$} \\
\hline Regret & $.50 * * *$ & & - & - & - & - \\
\hline SHS & $-.17 *$ & $-.22 * *$ & - & - & - & - \\
\hline
\end{tabular}

Note. Dashes indicate that data were not collected for this measure. Max $=$ Maximization Scale; Regret $=$ Regret Scale; SHS $=$ Subjective Happiness Scale; BDI $=$ Beck Depression Inventory; LOT $=$ Life Orientation Test; NR $=$ Neuroticism; SWLS $=$ Satisfaction With Life Scale.

$* p<.05 . \quad * * p<.01 . \quad * * * p<.001$.

was $.52(p<.001)$, and in the samples in which it was assessed, happiness and maximizing were significantly correlated $(r=$ $-.25, p<.001)$-as were maximizing and depression $(r=.34$, $p<.001)$.

\section{Gender Differences}

No gender differences were found in Samples $1-3$ or 5 in participants' scores on the Maximization Scale, the Regret Scale, or in the association between maximizing and measures of wellbeing and regret. In Samples 4, 6, and 7, a significant gender difference emerged - that is, males were more likely than females to be maximizers in all three of these samples: Sample $4(M \mathrm{~s}$ $=4.46$ vs. 4.27), $t(395)=2.41, p<.02$; Sample $6(M \mathrm{~s}=4.08$ vs. 3.79), $t(209)=2.26, p<.05$; and Sample $7(M \mathrm{~s}=4.33$ vs. 3.91$), t(107)=2.03, p<.05$.

\section{Partial Mediation by Regret}

Because questionnaires from Samples 1-3 and 5 included a common measure of depression and Samples 1-6 included a common measure of happiness as well as our maximization and regret scales, we were able to investigate a putative mechanism underlying the observed effects, namely, that the relations observed between maximization and both depression and happiness were mediated by a tendency to experience regret. According to R. M. Baron and Kenny (1986; see also Martin, Tesser, \& McIntosh, 1993), four criteria must be met to establish mediation: (1) the predictor variable (i.e., maximization) must be related to the criterion variable (e.g., depression); (2) the mediator (i.e., regret) must be related to the predictor; (3) the mediator must be related to the criterion (controlling for the influence of the predictor); and (4) the relation between the predictor and the criterion must be eliminated or significantly reduced when the criterion is regressed simultaneously on the predictor and the mediator. Turning first to depression, across the four samples, we observed a significant relation between maximization and scores on the BDI $(r=.34$, $p<.001$ ), meeting the first of the aforementioned criteria. In addition, regret and maximization were strongly correlated $(r=$ $.52, p<.001)$, meeting Criterion 2, and the relation between regret and depression $(r=.39)$ remained significant in a regression 
equation that controlled for the influence of maximization, $F(2$, $983)=105.45, p<.001$, regret $\beta=.29$; maximizing $\beta=.19$ (meeting Criterion 3). Finally, as this last multiple regression equation (which regressed depression simultaneously on regret and maximization) makes clear, although the relation between maximization and depression remained significant after controlling for regret, consistent with the dictates of Criterion 4, the relation was significantly weaker than it had been in the absence of regret (i.e., a change in beta from .34 to .19), an effect confirmed by a test based on Sobel's (1982) method for determining the existence of a mediational relation $(z=7.87, p<.001$; see also MacKinnon \& Dwyer, 1993; Preacher \& Leonardelli, 2001).

Similar analyses confirmed a mediational role played by regret in the relation between maximization and happiness, which were significantly negatively correlated across the six samples $(r=$ $-.25, p<.001)$. In brief, when regret, which was also negatively correlated with happiness $(r=-.37)$, was entered into a regression equation along with maximization as predictors of happiness, the aforementioned relation between maximization and happiness was significantly reduced (i.e., a change in beta from -.25 to $-.08)$, as confirmed by a Sobel test of mediation $(z=10.91, p<$ .001). In sum, regret appeared to play a partial mediational role between maximization and depression and between maximization and happiness. However, because of high correlations between regret and other constructs investigated in one or more samplesconstructs such as depression, happiness, and subjective wellbeing - any mediational role ascribed to regret should be viewed with caution. And, of course, regret was not manipulated in any of these samples, permitting no causal conclusions to be drawn.

\section{Discussion}

Study 1 provided evidence for individual differences in what people aspire to when they make decisions in various domains of their lives. Maximizers desire the best possible result; satisficers desire a result that is good enough to meet some criterion. When we correlated scores on our Maximization Scale with wellestablished measures of well-being, we found that maximizers reported significantly less life satisfaction, happiness, optimism, and self-esteem, and significantly more regret and depression, than did satisficers. Though Study 1 tells us nothing about the direction of causality, it is possible that whereas a maximizing decision strategy might, as a matter of logic, yield better objective outcomes than a satisficing strategy, it is likely to yield worse subjective outcomes. Study 1 also revealed that although maximizing was significantly correlated with perfectionism (Sample 6), the correlations of each of these measures with happiness and self-esteem in the study were quite different (happiness was negatively correlated with maximizing and positively correlated with perfectionism; self-esteem was negatively correlated with maximizing and uncorrelated with perfectionism), suggesting that maximizing and perfectionism are distinct.

Study 1 also tells us nothing about the stability over time of scores on the Maximization Scale. If a maximizing orientation is something like a trait, we would expect response patterns to be stable over time. Although a good deal more research is needed, Gillham, Ward, and Schwartz (2001) have collected repeated measures from 102 undergraduates, who were given the Maximization Scale four times over a period of 9 months. Scores at Time 1 correlated with scores at Time $2(r=.81)$, with scores at Time 3 $(r=.82)$, and with scores at Time $4(r=.73)$. Though larger samples and longer interevaluation intervals are essential before any firm conclusions can be drawn, these results suggest that a maximizing orientation enjoys some degree of stability.

How is a maximizer to judge whether a given outcome is the best possible outcome? In many cases, there is not a finite and transparent set of possibilities to allow for complete and unambiguous judgment. For example, what does it mean to have the best possible salary, meal at a restaurant, wardrobe, or even the best possible spouse? Although imagination could provide a standard, a more probable basis for the maximizer's assessment in these domains is social comparison (perhaps only with those seen as belonging to an appropriate comparison group). What does it mean to have ordered the best possible meal at a restaurant other than that it is better than anyone else's meal? Thus, whereas "good enough" usually can be judged in absolute terms, "the best possible" may often require social comparison. Being a maximizer may require one to be concerned with one's relative position.

Festinger (1954) and Frank (1985, 1999; see also Hirsch, 1976) have argued persuasively that people do seem to be guided largely by how they are doing relative to relevant others, and several studies that compared the effects of absolute and relative position on satisfaction have observed that good relative position produces greater satisfaction than good absolute position (Bazerman, Loewenstein, \& White, 1992; Bazerman, Moore, Tenbrunsel, WadeBenzoni, \& Blount, 1999; Blount \& Bazerman, 1996; Hsee, Blount, Loewenstein, \& Bazerman, 1999; Solnick \& Hemenway, 1998). Poor relative position, however, appears to affect some people more than others. For example, Lyubomirsky and Ross (1997) reported that unhappy people are more affected by upward social comparison than happy people. More specifically, in their first study, Lyubomirsky and Ross found that whereas both happy and unhappy people derived satisfaction from information that their performance was better than that of a peer, only unhappy people seemed to suffer from information that their performance was worse than that of a peer.

Especially relevant are the findings from Study 2 of the Lyubomirsky and Ross (1997) article. In that study, happy and unhappy students received positive or negative feedback from the experimenter on a novel teaching task, and then witnessed a same-sex peer receive even more positive or even more negative feedback than themselves. The most striking finding from this study was that unhappy students reported feeling happier and more self-confident when they had received a poor evaluation on their performance ( 2 out of 7 ), but heard their peer receive an even worse one (1 out of 7), than when they had received an excellent evaluation (6 out of 7), but heard their peer receive an even better one (7 out of 7). Happy students, by contrast, did not show this pattern of "sensitive" responding to comparisons with peers. These findings lend some credibility to our hypothesis that maximizers may be more concerned with relative position, and thus with social comparison, than satisficers, especially in light of the findings from Study 1 that maximizers are generally less happy than satisficers.

Studies 2 and 3 were designed to explore directly the relative importance of social comparison to maximizers and satisficers. Study 2 inquired about social comparison in the context of purchasing decisions. Study 3 replicated Lyubomirsky and Ross's 
(1997) first study with groups of participants identified as maximizers or satisficers.

\section{Study 2. Maximizing, Satisficing, Social Comparison, and Consumer Behavior}

Because many of the choices that people make in their daily lives concern the purchase and consumption of goods, Study 2 explored maximizing and satisficing with respect to consumer purchasing decisions. As indicated in the introduction, a proliferation of options can pose significant problems for a maximizer. One cannot be sure that one is making the best choice without examining all the alternatives. And if examination of all the alternatives is not feasible, then when the maximizer finally chooses, there may be a lingering doubt that he or she could have done better with more searching. Thus, as options increase, the likelihood of successful maximization goes down. Further, the potential for regret is ever present because the maximizer is asking "is this the best outcome?" and "could I have done better?" And in attempting to answer these questions, given the time and information-processing constraints that everyone faces, maximizers may be inclined to rely on information about how others are doing as a way of assessing whether their chosen outcomes were indeed the best. Thus, in Study 2, we were particularly interested in the relation between maximizing tendencies and social comparison, regret, and happiness with consumer purchasing decisions. We anticipated that maximizing would predict reports of engaging in more social comparison and experiencing greater regret in general. In addition, we expected that maximizing would predict reports of more product comparison, social comparison, and counterfactual thinking regarding purchases, and that these consumer comparisons would lead to heightened consumer regret and decreased happiness regarding purchases.

\section{Method}

\section{Participants, Materials, and Procedure}

Participants were the 401 undergraduates described earlier as Sample 4 in Study 1. The materials comprised a questionnaire that included the Maximization Scale, the Regret Scale, and the SHS from Study 1. In addition, we created a scale to measure frequency of social comparison in general, beliefs about the appropriateness of upward social comparison, and beliefs about the appropriateness of downward social comparison. ${ }^{1}$ In a pretest of this scale $(n=76)$, the subscales measuring frequency of social comparison $(\alpha=.69)$, upward social comparison $(\alpha=.74)$, and downward social comparison $(\alpha=.70)$ demonstrated adequate reliability. In addition, this pretest demonstrated that the frequency of social comparison subscale correlated with a validated measure of social comparison tendencies $(r=$ $.50, p<.001$; Gibbons \& Buunk, 1999).

Consumer behavior items were created regarding people's general tendencies toward consumer-related social comparison, product comparison, counterfactual thinking, and consumer regret. After completing these items, participants were asked to recall either an expensive or an inexpensive recent purchase. Participants in the inexpensive condition were asked to "recall the most recent item you have purchased that was relatively inexpensive, say around $\$ 5.00$. For example, the item might be a movie rental, a book, or a magazine." Those in the expensive condition were asked to "recall the most recent item you have purchased that was relatively expensive, say around $\$ 500.00$. For example, the item might be sporting equipment, electronic equipment, etc."
All participants then answered specific consumer behavior questions regarding their purchase, such as product price, product comparison, time to decide on the product, prepurchase and postpurchase social comparison, counterfactual thinking, happiness with the product, and regret regarding the recalled purchase. The order of presentation of the Maximizing and Regret Scales and the consumer behavior items was counterbalanced. Because counterbalancing did not predict significant variance in any of the dependent variables, the results are collapsed across this variable. Participants completed the questionnaire packet in class, and were debriefed at the end of the study.

\section{Results}

\section{Construction of Indexes}

Composites of social comparison frequency ( $\alpha=.68$ ), downward social comparison $(\alpha=.68)$, and upward social comparison $(\alpha=.71)$ were created. Composites also were constructed for general product comparison $(\alpha=.72)$, general social comparison $(\alpha=.72)$, and general consumer regret $(\alpha=.82)$. Finally, an index of consumer maximizing tendencies for a specific purchase was created by combining the measures of product comparison, time to decide, prepurchase social comparison, postpurchase social comparison, and counterfactual thinking $(\alpha=.81)$.

\section{Happiness, Regret, and Social Comparison Tendencies}

As reported in Study 1, maximizing was associated with being less happy (though this relation was modest) and experiencing more regret. We anticipated that maximizing also would predict reports of engaging in social comparison. A linear regression analysis with maximizing as the predictor on the overall index of social comparison frequency supported this prediction, $F(1$, $393)=39.07, p<.001, \beta=.30$. Regression analyses on the upward and downward social comparison indexes indicated that maximizing was also predictive of interest in upward, $F(1$, $397)=8.99, p<.01, \beta=.15$, and downward, $F(1,397)=21.14$, $p<.001, \beta=.23$, social comparisons. In addition, maximizing predicted reports of engaging in upward, $F(1,394)=33.63, p<$ $.001, \beta=.28$, and downward, $F(1,395)=15.09, p<.001, \beta=$ .19 , social comparisons more frequently.

Regression analyses indicated that both frequency of downward social comparison (when statistically controlling for frequency of upward social comparison), $F(2,392)=15.23, p<.001, \beta=.18$, and frequency of upward social comparison (when statistically controlling for frequency of downward social comparison), $F(2$, $392)=42.19, p<.001, \beta=.31$, were predictive of reports of

\footnotetext{
${ }^{1}$ In the interest of brevity, the items measuring social comparison frequency (e.g., "How frequently do you compare yourself to other people in general?"), appropriateness of upward social comparison (e.g., "Comparing oneself to those who are better off can be useful"), appropriateness of downward social comparison (e.g., "It is inappropriate to compare one's own standing to those who are not doing as well" [reverse scored]), general consumer behavior (e.g., for product comparison: "When I am planning to purchase an item of clothing, I like to look at all the stores first to make certain I get the perfect item"), and specific consumer behaviors (e.g., for product comparison: "How many products did you consider before choosing this particular one?") can be obtained from authors Katherine White (kjwhitek@interchange.ubc.ca) or Darrin R. Lehman (dlehman@cortex .psych.ubc.ca).
} 
regret. In addition, although frequency of downward social comparison (when statistically controlling for frequency of upward social comparison) was not predictive of subjective happiness, $F(2,392)=0.47, n s, \beta=.04$, upward social comparison frequency (controlling for downward social comparison) was, $F(2$, $392)=10.09, p<.01, \beta=-.16$.

Of interest, maximizers seemed to be oriented toward both upward and downward social comparisons. Past research and theorizing suggest that upward comparisons may trigger negative affective states, lead to low ratings of subjective well-being, and result in negative consequences for the self (e.g., Diener, 1984; Morse \& Gergen, 1970; Salovey \& Rodin, 1984), whereas downward comparisons often have the opposite effect, allowing the individual to feel better in comparison to a worse off other (e.g., Morse \& Gergen, 1970; Wills, 1981). The puzzle here is that although maximizing was predictive of engaging in more downward social comparison, it was also predictive of regret. Is it the case that maximizers are susceptible to the negative consequences of upward social comparison, but unable to reap the benefits of downward social comparison? This is not implausible in light of suggestive evidence that social comparison in general is not compatible with happiness (Lyubomirsky \& Ross, 1997; Lyubomirsky, Tucker, \& Kasri, 2001).

To address this possibility, we examined whether upward social comparison and downward social comparison were related to regret among those high in maximization. We performed a median split on the maximizing scale, and examined the relation between regret and social comparison among those scoring high on the maximizing scale. The results revealed that, among those high on maximizing, frequency of upward social comparison (controlling for downward social comparison) was predictive of regret, $F(2$, $197)=7.08, p<.01, \beta=.19$, whereas frequency of downward social comparison (controlling for upward social comparison) was not, $F(2,197)=2.50, p<.12, \beta=.11$. We also found that, among those high on maximizing, frequency of upward social comparison (controlling for downward social comparison) was predictive of decreased happiness, $F(2,198)=6.57, p<.02, \beta=$ -.18 , whereas frequency of downward social comparison (controlling for upward social comparison) was not positively related to happiness, $F(2,198)=.25, n s, \beta=.04$. This provides some support for the notion that whereas maximizers tend to experience the negative consequences of upward social comparisons, they are unable to benefit from downward social comparisons.

\section{General Consumer Behaviors}

Linear regression analyses on the general consumer behavior items revealed that maximizing predicted the tendency to engage in product comparison, $F(1,397)=42.49, p<.001, \beta=.31$, social comparison, $F(1,396)=12.27, p<.01, \beta=.17$, and counterfactual thinking, $F(1,397)=29.40, p<.001, \beta=.26$, regarding purchases. Further, maximizing was predictive of reports of consumer regret, $F(1,397)=19.16, p<.001, \beta=.22$.

\section{Consumer Behaviors for Recalled Purchases}

Participants were asked to report on either an inexpensive or an expensive purchase. The average amount spent on inexpensive purchases was $\$ 6.57$, and maximizing was not predictive of the amount spent on inexpensive purchases $(F<1, n s)$. The majority of inexpensive purchases were magazines $(22.4 \%)$, movie rentals (22.0\%), food $(15.1 \%)$, and books $(10.7 \%)$. Other inexpensive purchases included such things as cosmetics, school supplies, and CDs. The average amount spent on expensive purchases was $\$ 538.00$, and, once again, maximizing was not predictive of the amount spent $(F<1, n s)$. The majority of expensive purchases were stereo equipment $(16.8 \%)$, computers $(15.8 \%)$, and clothing $(15.3 \%)$. Other expensive items included sporting equipment and other electronic items (e.g., TVs, cell phones).

Regression analyses indicated that, when recalling a specific purchase, maximizing predicted the consideration of more products, $F(1,389)=5.23, p<.01, \beta=.12$, and taking longer to decide, $F(1,390)=13.13, p<.001, \beta=.18$. Maximizing predicted reports of engaging in social comparison both before, $F(1,390)=4.51, p<.04, \beta=.11$, and after, $F(1,390)=5.52$, $p<.02, \beta=.12$, making purchases. Furthermore, maximizing was associated with engaging in more counterfactual thinking regarding purchases, $F(1,390)=34.12, p<.001, \beta=.28$. Finally, maximizing was predictive of reports of diminished positive feelings toward purchases (i.e., an index of happiness and regret, with regret reverse scored), $F(1,389)=9.68, p<.01, \beta=$ -.16 . Thus, it appears that maximizers not only report engaging in more comparisons (i.e., product comparisons, social comparisons, and counterfactual comparisons) regarding their consumer decisions, they also report experiencing heightened regret and decreased happiness.

Given the relation between maximizing and happiness observed in these studies, it is possible that findings that we have attributed to individual differences in maximizing may really be due to differences in dispositional happiness, a plausible hypothesis given Lyubomirsky and Ross's (1997) finding that unhappy people are more affected by upward social comparison information than happy people. To examine this possibility, we conducted partial correlation analyses between maximizing and regret, frequency of social comparison, maximizing tendencies (i.e., an index of time to decide on the purchase, product comparison, prepurchase social comparison, postpurchase social comparison, and counterfactual thinking), and consumer feelings (i.e., an index of consumer happiness and regret), controlling for dispositional happiness. The partial correlations between maximizing and regret $(r=.39, p<$ $.001)$, frequency of social comparison $(r=.27, p<.001)$, maximizing tendencies $(r=.19, p<.001)$, and consumer feelings $(r=-.13, p<.02)$ all remained significant when levels of happiness were statistically controlled. Thus, it appears that maximizing makes a contribution to regret, to social comparison, to consumer behaviors, and to consumer satisfaction over and above that of dispositional happiness.

\section{Discussion}

As anticipated, maximizing was predictive of reports of engaging in social comparison, being concerned with what others were doing, and finding upward and downward social comparison more appropriate. Maximizing also predicted product comparison, social comparison, and counterfactual thinking with regard to purchases. Moreover, maximizing predicted consumer feelings, such that those high on maximizing ultimately experienced more regret and less happiness regarding their purchases. These patterns held after 
controlling for dispositional happiness. Furthermore, our findings regarding consumer behavior suggest that social comparisons and product comparisons stimulated counterfactual thoughts, which then engendered regret (see, e.g., Roese, 1997). Although a measure of general counterfactual thinking was not included in this study, recent research indicates that maximizers ruminate more than satisficers (White, Lehman, \& Schwartz, 2002). It may be the case that counterfactual thinking and ruminative thoughts are related to the general regret reported by maximizers, as well as to consumption-related regret. Thus, it appears that striving for the best things in life may have paradoxical consequences.

Intuition, along with previous research (e.g., Morse \& Gergen, 1970), suggests that whereas upward social comparison might yield regret and unhappiness, downward social comparison might yield elation. Study 2 found no such mood enhancing effects of downward social comparison. However, a close look at the recent literature on social comparison suggests that consistent positive effects of downward social comparison are reliably reported only for individuals who have low self-esteem or experience physical or psychological threat (e.g., Affleck \& Tennen, 1991; Aspinwall \& Taylor, 1993; Gibbons \& Gerrard, 1989; Taylor, 1983; see Wills, 1991, for a review). In the general population, the mood effects of social comparison are much less predictable. Recent findings suggest that the affective consequences of social comparison are not intrinsic to its direction (e.g., Buunk, Collins, van Yperen, Taylor, \& Dakof, 1990). That is, both upward and downward comparisons can have positive or negative implications for the self (e.g., Brewer \& Weber, 1994; Brown, Novick, Lord, \& Richards, 1992; Buunk et al., 1990; Hemphill \& Lehman, 1991; Lockwood \& Kunda, 1997; Taylor, Buunk, \& Aspinwall, 1990; Tesser, 1988; Wood \& VanderZee, 1997).

A limitation of Study 2 is that although it relied on reports of real-life experiences, these were merely recalled by participants. Because participants' recollections of the purchasing situation could be biased or incomplete, it is important to assess social comparison, happiness, and regret among maximizers and satisficers in other settings as well. Thus, Study 3 attempted to examine reactions to social comparison information in a controlled laboratory setting.

\section{Study 3. Maximizing, Satisficing, and Social Comparison}

Because maximizers are continually chasing the best possible option when making a decision, they try to gather and analyze all of the information available to them. Information about one's relative standing with one's peers-that is, social comparison information-is likely to be an important source of information in their decision-making process. Thus, maximizers are expected to be more interested in social comparison feedback and more sensitive to such feedback than satisficers.

Accordingly, the primary hypothesis tested in Study 3 was that the moods and self-evaluations of maximizers would be more vulnerable or sensitive to unsolicited social comparison information than would those of satisficers. This study asked participants to solve anagrams at whatever rate they were capable, but manipulated the ostensible performance of an undergraduate peer so that participants experienced relative "success" (i.e., their peer performed worse than themselves) or relative "failure" (i.e., their peer performed better than themselves). This paradigm was developed by Lyubomirsky and Ross (1997, Study 1), who found support for a parallel prediction regarding chronically unhappy and happy individuals. That is, in their study, self-rated unhappy students who solved puzzles in the presence of a faster peer showed smaller increases in mood and self-confidence and expressed greater doubts about their own ability than those exposed to a slower peer. Happy individuals, by contrast, did not exhibit this pattern of sensitive responding to social comparison feedback.

Study 3 was characterized by several notable features. First, to minimize possible experimental demand characteristics and suspicion on the part of participants, and to simulate typical "realworld" peer comparison contexts, social comparison information was provided indirectly. That is, the experimenter never explicitly offered any comparison of performances, although such information was made highly salient to the participants. Second, the relevant task and dimension of evaluation (i.e., anagram-solving ability) was one about which participants were unlikely to have objective standards for evaluating their performance. Finally, participants enjoyed wide latitude in managing the social comparison information they faced. That is, they were free to minimize or maximize the relevance, importance, and controllability of the evaluation dimension; they were free to compete with, identify with, or simply ignore their more or less successful peer; and they were free to attribute their own performance and/or that of their peer to whatever factors they wished.

To summarize, whereas in Study 2, participants only responded to questions regarding their social comparison tendencies in connection with consumer choices, Study 3 used a more powerful and more direct manipulation of social comparison information, one involving a real-life peer performing alongside the participant in the laboratory. And in Study 3, rather than measuring participants' interest in and seeking of such comparison information, we examined the actual effects of social comparison information provided by the context.

\section{Method}

\section{Overview}

In the context of a purported study of cognitive performance, maximizers and satisficers (as categorized by their earlier responses to the Maximization Scale) solved anagram puzzles while a supposed peer (who was actually an experimental confederate) ostensibly completed the same set of anagrams much faster or much slower than themselves. Participants rated themselves with respect to their current mood and anagram-solving ability both before and after completion of the anagram-solving task.

\section{Participants}

Fifty-four students enrolled in an introductory psychology course at the University of California, Riverside received course credit for their participation in this study. Participants were selected on the basis of their responses to the 13-item Maximization Scale, which was presented in the context of a mass-administered questionnaire $(n=82)$. Responses to the 13 items, which displayed good internal consistency $(\alpha=.79)$, were combined and averaged to provide a single composite score, ranging from 2.6 to 6.7 , with a median of 4.2 on the 7 -point scale.

A sample of 26 maximizers and 28 satisficers, that is, those whose composite scores were respectively either in the top or bottom third of the distribution, were recruited for the study by telephone. The maximizers' group mean on the Maximization Scale was $5.26(S D=0.50)$, whereas the 
satisficers' group mean was $3.49(S D=0.43)$. We should note that the omnibus questionnaire used in selecting these participants also included the SHS and BDI (Beck, 1967). The correlations between participants' scores on the Maximization Scale and their scores on the SHS and BDI were moderate to high ( $r=-.27$ and $r=.46$, respectively). The inclusion of these scales, although not specifically intended for this purpose, allowed us to pursue issues of discriminant validity.

\section{Procedure and Materials}

In each experimental session, two individuals-a participant and a same-gender confederate pretending to be another participant-completed the relevant questionnaires and experimental tasks together. The experimenter, who was unaware of participants' maximization status, explained that participants were being paired simply to "save time."

The experiment was introduced as a study of "cognitive performance"that is, one in which "we hoped to learn how personality and various situational variables affect performance on a problem-solving task." Accordingly, participants were told they would be asked to solve a series of anagram puzzles during the experimental session. To bolster this cover story, a number of filler items, including questions about how often participants solved puzzles and how much they enjoyed them, as well as their quantitative and verbal Scholastic Assessment Test (SAT) scores, were embedded in the various questionnaires administered throughout the study.

Before undertaking the primary experimental task, participants completed a preliminary questionnaire assessing their premanipulation or "baseline" mood. Mood was assessed with the Positive and Negative Affect Schedule (PANAS; Watson, Clark, \& Tellegen, 1988), with 10 items measuring positive affect (PA; $\alpha=.87$ ) and 10 items measuring negative affect (NA; $\alpha=.79)$ on 5-point Likert-type scales. Participants also provided a baseline measure assessing how good they initially thought they were at solving anagrams $(1=$ very poor, $7=$ excellent $)$.

Anagram-solving task and social comparison manipulation. After the participants had completed the preliminary questionnaire, a female experimenter gave instructions for the 15-min anagram-solving task, which closely followed a procedure developed by Lyubomirsky and Ross (1997, Study 1). She began by handing each of them a "sample" puzzle card containing three anagrams-that is, $Y-O-W-N-S$ (SNOWY), N-O-T-I-X (TOXIN), and $A-S-S-I-B(B A S I S)$ — and indicating that such cards would be used throughout the anagram task. She further explained that upon unscrambling any two of the three anagrams on a given card, they were to write their solutions and the card number on their answer sheet, then hand the card back to the experimenter and receive a new card containing new anagrams. Participants were also given a notebook to use as scratch paper (one page per card). At that point, the experimenter instructed them to begin solving anagrams and handing in their cards. What the participants did not know was that their coparticipant was an experimental confederate who had been instructed to monitor their partner's pace and solve either approximately twice as many or half as many anagrams as he or she did-a task that they accomplished successfully. The back-and-forth handing of the anagram cards as the participant and confederate worked side-by-side throughout the 15-min period, along with the consecutive numbering of the cards and the turning of notebook pages, served to make it highly salient to participants that their peer was performing at a much faster or much slower pace.

Postperformance questionnaires. Immediately following the 15-min anagram task, the participant and confederate were led to separate rooms, and the participant was asked by the experimenter to complete a second set of self-assessments. To assess participants' changes in mood as a function of their own performance in the two social comparison conditions, participants were asked to complete the PANAS for a second time $(\alpha=.92$ and $\alpha=.83$ for the PA and NA scales, respectively). To assess changes in participants' perceptions of their own ability in light of their performance and the apparently superior or inferior performance of their peer, participants were asked to rate again how good they thought they were at solving anagrams $(1=$ very poor, $7=$ excellent $)$. As a manipulation check, participants were next asked to rate their own just-completed task performance and that of the confederate using 7 -point scales $(1=$ very poor, $7=$ excellent).

Finally, when all dependent variables had been collected, participants completed a debriefing questionnaire and engaged in an oral debriefing, in which they were given an opportunity to share their hunches about the hypothesis of the study and to report any other suspicions. No guesses or notable suspicions were reported. The entire session, including a process debriefing (Ross, Lepper, \& Hubbard, 1975), lasted approximately $1 \mathrm{hr}$.

\section{Results}

\section{Premanipulation Measures}

Measures completed prior to the anagram-solving task suggested no between-group differences in ability or experience. That is, maximizers and satisficers did not differ significantly in their quantitative and verbal SAT scores, in their initial self-ratings of ability at solving anagrams, in their reports of how often they solved anagrams, or in how much they enjoyed solving them (all $t \mathrm{~s}<1$ ). Notably, the two groups also did not differ significantly in their baseline moods ( $t$ s for both PA and NA $<1$ ).

\section{Manipulation Check}

Overall, participants solved a mean of 12.7 anagrams $(S D=7.84)$ during the allotted 15 -min test period. Analyses revealed no significant performance differences between satisficers and maximizers overall, $t(53)=1$, or in either the "faster peer" $(t<2)$ or "slower peer" $(t<1)$ conditions. Nor was any main effect found for peer performance on the participants' own performance, $t(43)=0.74, n s$. As instructed, the confederate, depending on experimental condition, "solved" either considerably more anagrams $(M=27.29 ; S D=8.53)$ or considerably fewer anagrams $(M=8.01 ; S D=5.90)$ than the participant. The participants, moreover, showed themselves to be well aware of these performance differences. Those in the "faster peer" condition rated their peer as significantly better at solving anagrams $(M=6.07, S D=0.94)$ than did those in the "slower peer" condition $(M=3.08, S D=0.93), t(51)=11.73, p<.001$ Finally, participants who witnessed a faster peer rated themselves as significantly worse at solving anagrams $(M=2.29, S D=1.15)$ than did those who witnessed a slower peer $(M=3.81$, $S D=1.52), t(46)=4.12, p<.001$.

\section{Strategies for Statistical Analyses}

We hypothesized that maximizers' moods and self-assessments of ability would depend heavily on the quality of their peer's performance - that is, whether it was inferior or superior to their own. Satisficers' moods and self-assessments, by contrast, were expected to be less influenced by the performance of their peer. We conducted planned pairwise comparisons of the faster peer and slower peer conditions within the two groups (Rosenthal \& Rosnow, 1985; see also Rosnow \& Rosenthal, 1989, 1995). Additionally, we compared maximizers who had witnessed a faster peer with those in the three remaining conditions. Simple change scores reflecting differences between premanipulation and postmanipula- 
tion ratings provided the primary dependent variables for both types of analyses. Other types of statistical analyses, such as analyses of covariance (ANCOVAs) and repeated measures analyses, were also performed and yielded results very similar to those obtained in the analyses reported in this article. For brevity, these results are not discussed.

\section{Changes in Self-Assessments of Ability}

We expected maximizers to offer ratings of their own ability that gave considerable weight to social comparison information. Supporting this prediction, a planned contrast revealed that maximizers gave lower assessments of ability on the anagram task after working alongside a faster peer $(M=-1.71, S D=1.27)$ than after working alongside a slower peer $(M=0.17, S D=1.11), F(1$, $50)=10.34, p<.003$. Self-assessments of satisficers, by contrast, did not differ significantly between the two social comparison conditions $(M \mathrm{~s}=-0.79$ vs. 0.14$), F(1,50)=2.63$. The top panel of Figure 1, as well as the top of Table 3, shows the mean changes in self-assessments of ability, based on 7-point rating scales, for all four groups.

As expected, maximizing participants in the "faster peer" condition not only exhibited the largest relative decline in self- assessments of the four groups, $F(1,50)=11.33, r=.43, p<$ .002 , but their mean decline was the only one of the four that was significantly different from zero $(M=-1.71), t(14)=5.06, p<$ .001. However, differences between the responses of maximizers and satisficers in this condition-at least in terms of changes in their self-assessments of ability - did not reach conventional levels of statistical significance, $F(1,50)=2.73, p<.10$.

\section{Changes in Self-Reported Affect}

Examination of changes in participants' self-reported negative mood (NA) produced a similar pattern of results (see the bottom panel of Figure 1 and the top of Table 4). Once again, supporting our predictions, maximizers displayed significantly more elevated NA after witnessing a faster peer $(M=0.54, S D=0.82)$ than after witnessing a slower peer $(M=-0.03, S D=0.50), F(1,50)=$ $6.31, p<.02$. Satisficers, by contrast, showed more similar affect in response to their superior versus inferior peer's performance $(M \mathrm{~s}=0.12$ vs. -0.06$), F<1$.

Following the pattern of results for self-assessments, maximizers in the "faster peer" condition not only exhibited the biggest increase in NA of the four groups, $F(1,50)=8.70, p<.005$, but, once again, their mean increase was the only one of the four groups
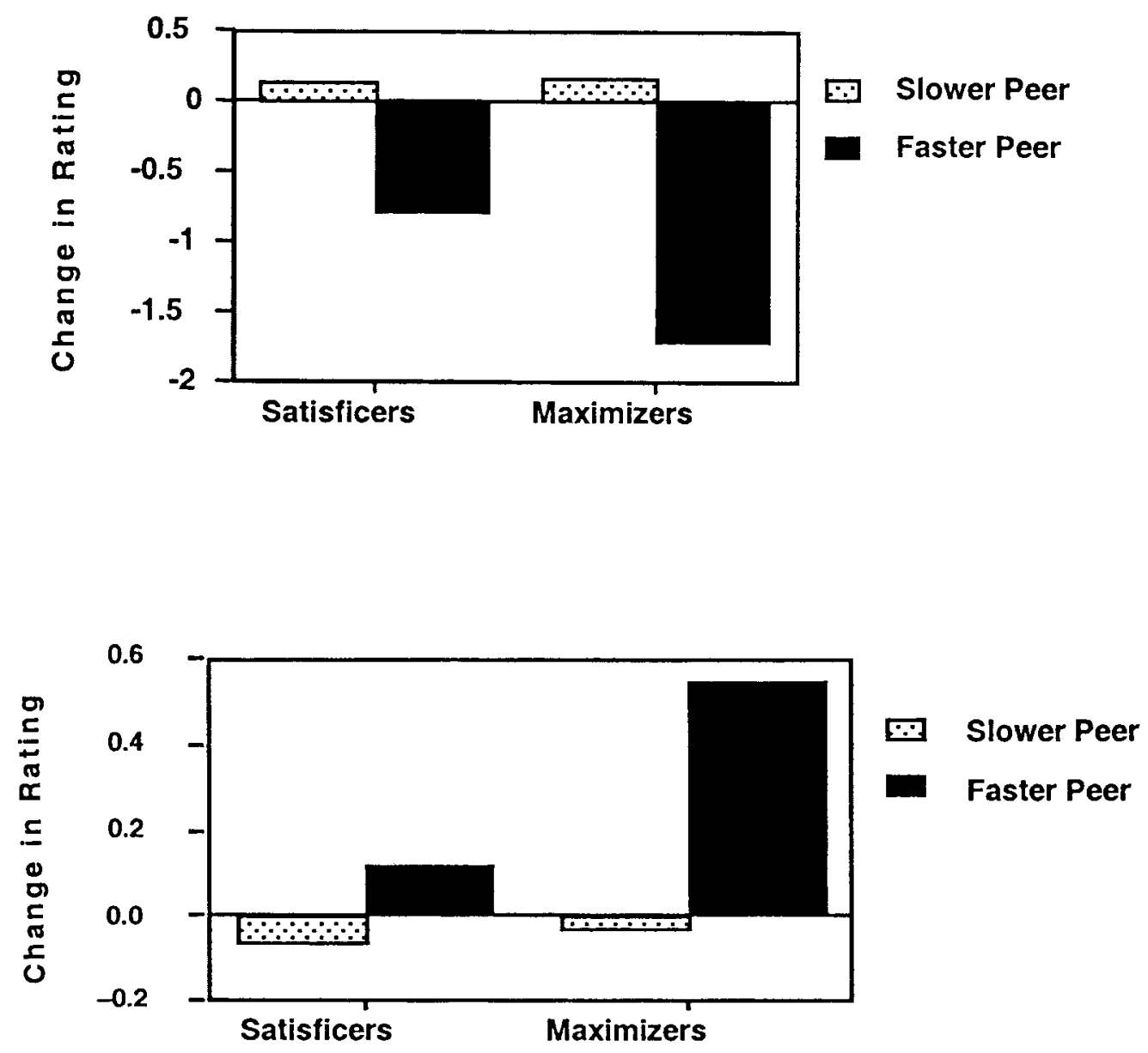

Figure 1. Changes in assessments of ability (top) and negative affect (bottom) after working alongside a slower versus faster peer (Study 3). 
Table 3

Maximization Versus Happiness and Dysphoria in Determining Changes in Participants' Self-Assessments of Ability in Response to a Faster Versus Slower Peer

\begin{tabular}{lcr}
\hline & \multicolumn{2}{c}{ Group } \\
\cline { 2 - 3 } Condition & Maximizers & Satisficers \\
\hline & Raw means & \\
Faster peer & -1.71 & -0.79 \\
Slower peer & -0.17 & 0.14 \\
Difference & 1.88 & 0.93 \\
\hline
\end{tabular}

Adjusted means (with SHS score as covariate)

\begin{tabular}{lrr} 
Faster peer & -1.98 & -0.57 \\
Slower peer & -0.16 & -0.47 \\
Difference & 1.82 & 1.04 \\
\hline
\end{tabular}

Adjusted means (with BDI score as covariate)

\begin{tabular}{lrr} 
Faster peer & -1.88 & -0.65 \\
Slower peer & 0.00 & 0.32 \\
Difference & 1.88 & 0.97 \\
\hline
\end{tabular}

Note. SHS $=$ Subjective Happiness Scale; BDI $=$ Beck Depression Inventory.

that was significantly different from zero $(M=0.54)$, $t(14)=2.43, p<.03$. Furthermore, differences between the responses of maximizers and satisficers in this condition were marginally statistically significant, $F(1,50)=3.62, p<.07$. None of the analyses examining group differences in changes in participants' positive mood (PA) reached conventional levels of statistical significance.

\section{Subjective Happiness and Dysphoria as Possible Moderator Variables}

Readers might question whether the effects reported thus far really reflect the role of a maximization orientation rather than that of chronic happiness or dysphoria. Indeed, similar effects have been reported in an analysis of dispositionally happy and unhappy individuals (Lyubomirsky \& Ross, 1997, Study 1). Given the moderately high correlations in this study between participants' scores on the Maximization Scale and their scores on the SHS and the BDI, it was deemed prudent to address this question through covariance analyses.

With respect to both happiness (as measured by the SHS) and dysphoria (as measured by the BDI), the results of our analyses were simple and conclusive. When either happiness or dysphoria was introduced as a covariate, neither variable accounted for our between-group differences. That is, both for changes in selfassessment of ability and for changes in NA, ANCOVAs left our "adjusted" means for both ability change (see Table 3 ) and NA change (see Table 4), as well as the relevant contrasts, virtually unaltered in magnitude.

\section{Discussion}

The results of Study 3 supported our hypothesis that maximizers would be more affected by social comparison information than would satisficers. Maximizers who saw their peer solve anagrams faster than themselves expressed greater doubts about their own ability at the task and displayed a greater increase in negative mood than maximizers who saw their peer solve fewer anagrams. Satisficers, by contrast, showed little or no such response to the social comparison information provided by their peer. Subsequent analyses, moreover, suggested that it was differences in maximization per se, rather than the association of maximization with happiness or dysphoria, that predicted the relevant differences in response.

Although the focus of this study was on the ways that students use self-relevant social comparison feedback when evaluating themselves, the relevant social comparison processes are likely to mirror those recruited in decision-making contexts of the sort investigated in Study 2. We suspect that many decisions faced by students - for example, which major to choose, to which graduate school to apply, which job to select-involve self-evaluations, and comparisons with peers can provide feedback about whether one can "cut it" in a particular major, school, or job. We speculate that because satisficers are satisfied with a major, school, or job that is simply "good enough," they may not require as much information in general-and social comparison information in particular-as do maximizers in order to make decisions.

Several issues raised by Study 3 deserve comment. First, given that changes in participants' PA did not show the expected pattern of results, further research could test the possibility that it is on NA that social comparison has its major influence. Second, because the current study examined differences in maximizers' and satisficers' responses to social comparison information and not their interest in or seeking of such information, the latter topics remain worthy of investigation (though the questionnaire responses in Study 2 suggest that maximizers seek more social comparison information than satisficers). And, finally, because Study 3 was conducted in

Table 4

Maximization Versus Happiness and Dysphoria in Determining Changes in Participants' Self-Reported Negative Affect in Response to a Faster Versus Slower Peer

\begin{tabular}{lcr}
\hline & \multicolumn{2}{c}{ Group } \\
\cline { 2 - 3 } Condition & Maximizers & Satisficers \\
\hline & Raw means & \\
& & 0.12 \\
Faster peer & 0.54 & -0.06 \\
Slower peer & -0.03 & 0.18 \\
Difference & 0.57 & \\
\hline
\end{tabular}

Adjusted means (with SHS score as covariate)

\begin{tabular}{lrr} 
Faster peer & 0.62 & 0.06 \\
Slower peer & 0.06 & -0.16 \\
Difference & 0.56 & 0.22 \\
\hline
\end{tabular}

Adjusted means (with BDI score as covariate)

\begin{tabular}{lrr} 
Faster peer & 0.63 & 0.04 \\
Slower peer & 0.07 & -0.17 \\
Difference & 0.56 & 0.21 \\
\hline
\end{tabular}

Note. $\quad$ SHS $=$ Subjective Happiness Scale; BDI $=$ Beck Depression Inventory. 
the laboratory, the question remains how maximizers and satisficers respond to social comparison feedback during the course of decisions in their everyday life.

Taken together, our findings in Studies 2 and 3 provide support for the notion that maximizers are more likely than satisficers to seek out and respond to social comparison information each time they try to make the "perfect choice."

\section{Study 4. Maximizing, Satisficing, and Regret}

The first three studies have provided evidence of individual differences in the disposition to maximize that correlate with other important variables and are reflected in self-reports about purchasing decisions. Further, there is evidence, both from self-report and experimental data, that maximizers are more inclined to engage in social comparisons and to be more sensitive to their contents than are satisficers. The final study reported here tested whether a disposition to maximize relates to actual decision-making behavior. We created a game that required participants to make decisions, and investigated whether maximizers made different decisions, and experienced different degrees of satisfaction from those decisions, than did satisficers.

The second aim of Study 4 was to explore experimentally the relation between maximizing and regret. We reported in Study 1 consistent and substantial correlations between scores on our Maximization Scale and scores on our Regret Scale. We also reported evidence that partially supported the hypothesis that regret mediates the relations between maximization and various measures of well-being. On the basis of this evidence, we suggested that one of the factors that may lead maximizers to experience less happiness and satisfaction with life than satisficers is maximizers' increased sensitivity to regret-both experienced and anticipated. If that is true, then it should be the case that experimental manipulations designed to enhance the possibility of experiencing regret should have a larger impact on maximizers. The game used in Study 4 was designed to manipulate the potential to experience regret.

We used a variant of the ultimatum game (Camerer \& Thaler, 1995; Guth, Schmittberger, \& Schwarze, 1982). In the ultimatum game, one player has control of a resource (typically a sum of money) and offers some part of that resource to another player. That player may either accept the offer, in which case the resource is divided in keeping with the offer, or reject it, in which case neither player gets anything. This game has been of interest to experimental economists because an analysis of optimal strategy by a rational maximizer of gain would seem to dictate that the proposer make the smallest legal offer, secure in the knowledge that the recipient of that offer will accept it (a little of something is better than nothing). This pattern is virtually never observed among actual participants. First, recipients of offers routinely reject them if they are too low (e.g., less than $30 \%$ of the resource). Second, proposers rarely make such low offers.

With respect to regret, there is an interesting asymmetry to the ultimatum game. The proposer will always know if he or she has made an offer that is too low, because the recipient of that offer will have rejected it. However, the proposer will not know if the offer was too high because there is no information about the minimum acceptable offer-the reservation price. When the recipient accepts the offer, it could be that the offer was at exactly the price necessary for acceptance or that it was higher than necessary.
Thus, one would expect proposers who are worried about regretting their decisions to make unnecessarily high offers. That way, they will avoid the only source of regret that the situation permits-an offer that is rejected. Suppose, however, that the game were altered so that proposers would be told what the minimum acceptable offer was on trials of the game in which their offers were accepted. Thus, they might offer $\$ 5$ of a $\$ 10$ stake, have their offer accepted, and then find out that an offer of $\$ 3$ also would have been accepted. Under these conditions, it is possible to regret offers that are too high just as it is possible to regret offers that are too low. Zeelenberg and Beattie (1997) found that offers in this modified ultimatum game tended to be lower than offers under the standard procedure. Our question, based on the hypothesis that maximizers are more sensitive to regret than satisficers, was whether the effect observed by Zeelenberg and Beattie would be larger for maximizers than for satisficers.

\section{Method}

\section{Participants}

The participants were 84 students ( 48 female and 36 male) enrolled in an introductory psychology course at Swarthmore College who received course credit.

\section{Procedure}

All participants had previously completed a packet of questionnaire materials including the Maximization Scale and the Regret Scale. Approximately 7 weeks later, participants were directed to a Web site for participation in another study. They were given 2 weeks in which to do the tasks on the Web site at a time and place that was convenient to them. About $75 \%$ of the participants completed the tasks within the allotted time. The others were sent follow-up reminders by e-mail until all but 7 had complied. No mention was made of the connection between this study and the questionnaire materials they had completed earlier.

Each participant played two versions of the ultimatum game, in counterbalanced order: a "standard" version and a modified version (they differed in only one respect, described below). Each version included 10 rounds. In the standard version, participants first encountered a screen that told them that they were "Player 1," that the computer would be "Player 2," and that the computer would be making decisions based on the performance of real people playing the identical game. Participants were also told that on each round, they would be given a sum of money (between $\$ 8$ and $\$ 15)$. They were to make a whole dollar offer to Player 2 (the computer), who would know what amount of money was being divided on each round, and could accept or reject the offer. Participants were further informed that the computer would simulate Player 2's responses on the basis of past behavior of people who have played this game. Moreover, it was explained, on each round, a different past player would be used for the simulation, so participants were to treat each round as playing with a different Player 2. For each round, if the participant's offer was accepted, Player 2 (the computer) would "get" the amount offered, while Player 1 (the participant) would get the difference between the total amount and the amount offered. Thus, for example, if a round started with $\$ 12$ available, and Player 1 made an offer of $\$ 5$ that was accepted, Player 2 would get the $\$ 5$, and Player 1 would get $\$ 7$. If the offer was rejected, neither player would get anything. Participants were also told that there was a chance that they would actually get to keep whatever amount resulted from a given round of the game. At the end of each round, participants were asked to click the mouse along an unmarked line that was anchored on the left with very unsatisfied and on the right with very satisfied to indicate their satisfaction with that round of the game. 
In the modified version, to which all participants also were exposed, at the end of a round, in addition to being told whether their offer was accepted or rejected, they were also told what the smallest offer was that Player 2 would have accepted-Player 2's "reservation price." The reservation price of Player 2 was programmed to vary pseudorandomly, with a low of $13 \%$ of the initial sum and a high of $57 \%$ of the initial sum. The idea behind this manipulation was that in the standard game, players never know that they have offered more than was necessary, and thus will not experience regret over offers that are too high. In this variant of the game, participants would know when they had made offers that were more generous than necessary.

\section{Results and Discussion}

Participants offered their counterpart half of the initial sum of money (rounded to the nearest dollar) on $53.4 \%$ of trials, less than half on $37.3 \%$ of trials, and more than half on $9.3 \%$ of trials. Given the low rates of offers above half, the data were collapsed into offers of less than half (37.3\%) and offers of at least half $(62.7 \%)$. No significant difference in rates of offering less than half was found between males and females $(42.2 \%$ vs. $33.4 \%$ for males vs. females, respectively; $t<1.5$ ). Maximization score was not correlated with the percentage of offers made below half $(r=.15$, $n=82, n s$ ). However, an ANCOVA (with maximization score as a continuous variable) revealed that there was a significant interaction between gender and maximization score on the number of offers made of less than half, $F(1,82)=6.80, p<.01$. The relation between maximization score and offers made was thus analyzed separately for males and females. Among males, participants higher in maximization exhibited a significantly higher percentage of offers below half $(r=-.40, n=35, p<.02)$. Among female participants, no significant association was found between maximization score and the percentage of offers below half $(r=.14, n=47, n s)$.

Within-participant $t$ tests comparing offers made on trials in which the reservation price of opponents was shown versus those in which it was not shown did not indicate any difference in the percentage of offers of less than half $(38.4 \%$ vs. $36.0 \% ; t<1)$. Thus, we failed to replicate the findings of Zeelenberg and Beattie (1997) for the participants as a group. However, experimental condition did interact with maximization scores in predicting the number of offers made of less than half by each participant. Using a repeated measures analysis of variance (ANOVA), with experimental condition (i.e., whether or not reservation prices were shown) as the repeated factor, there was a significant Condition $\times$ Maximization interaction in the percentage of offers made below half, $F(1,80)=8.90, p<.004$. That is to say, satisficers and maximizers tended to adjust their offers differently on the basis of whether reservation prices were shown.

To determine the basis of the interaction between experimental condition and maximization score on offers made, participants were divided into satisficers and maximizers on the basis of a median split. Among satisficers, participants exhibited lower rates of offers of less than half on rounds in which reservation prices were seen as compared with those in which reservation prices were not seen (32.2\% vs. $39.4 \%$, respectively), $t(40)=2.42, p<.02-\mathrm{a}$ surprising result given what Zeelenberg and Beattie (1997) found. Maximizers, however, did the opposite, confirming our expectations. They revealed higher rates of offering less than half on trials in which reservation prices were seen as compared with those in which reservation prices were not seen $(48.1 \%$ vs. $35.9 \%$, respectively), $t(40)=3.42, p<.001$.

As would be expected, mean ratings of satisfaction were considerably higher on rounds in which the participants' offer was accepted $(M=7.02)$ than on those in which it was rejected $(M=3.18), t(80)=13.40, p<.001$. Controlling for whether offers were accepted, higher maximization scores predicted lower judgments of satisfaction, $F(1,81)=7.60, p<.01$. Thus, being a maximizer seemed to mean being less satisfied with the results of an episode, independent of what those results were. Judgments of satisfaction did not differ by condition ( 5.88 vs. 5.97 , for standard vs. modified version, respectively; $t<1$ ). Further, no interaction was present between condition and maximization scores in predicting judgments of satisfaction $(F<1)$.

On the basis of a repeated measure ANOVA, there was a trend suggesting an interaction between maximization score and the acceptance of offers as predictors of judgments of satisfaction, $F(1,74)=2.60, p<.11$. To explore this trend, the associations between maximization score and ratings of satisfaction were assessed separately for those rounds in which offers were rejected and those in which offers were accepted. No significant correlation was found between maximization score and judgments on those trials in which offers were rejected ( $r=-.07, n=77, n s)$, but participants higher in maximization were relatively less satisfied during rounds in which offers were accepted $(r=-.31, n=82$, $p<.005)$. This negative correlation was present both on rounds in which reservation prices were shown $(r=-.30, n=82, p<$ $.006)$, and those in which reservation prices were not shown $(r=$ $-.28, n=81, p<.02$ ).

To summarize, the results of Study 4 were consistent with many, but not all, of our predictions. In the ultimatum game, male (but not female) maximizers made smaller offers than male satisficers. Maximizers of both genders offered less when the recipient's reservation price was going to be revealed (as we expected), but unexpectedly, satisficers offered more when the recipient's reservation price was going to be revealed. Finally, as hypothesized, maximizers were less satisfied than satisficers with outcomes generally. However, they were not especially dissatisfied in the condition in which reservation price was revealed, as had been expected.

The observed interaction on offers made between Maximization scores and gender may reflect the presence of implicit social payoffs present in the task. The presumed incentive to make lower offers when reservation prices are revealed rests on the expectation that finding out that larger gains could have been made will invite regret. To the extent that participants experience the game as a social interaction, however, this may not be the case. Most obviously, motivations of cooperation and fairness may result in the experience of maximal utility with an even split as opposed to one in which the participant gets more than half the money. However, the social motive of competitiveness might result in higher utility for the more financially favorable split. So it is possible that the fact that males, but not females, tended to make lower offers when reservation prices were revealed may reflect a greater display of social motivation toward cooperation and fairness among females and/or greater social motivation toward competitiveness among males. Indeed, it is further possible that, particularly in a situation with little truly at stake, the presence of feedback indicating that the possibility to exploit was present but not taken (the condition 
with known reservation prices) could make the choice of an equitable split even more rewarding to participants with social motives favoring equity. If so, this might explain the tendency of satisficers to offer more 50-50 splits in the condition in which reservation prices were revealed than when they were hidden.

Finally, the fact that maximizers were not particularly dissatisfied with the condition in which reservation prices were revealed (thus inviting more regret) might have been due to the above reported interaction between condition and maximizing score on offers made. Maximizers tended to make lower offers in the condition in which reservation prices were shown, which may have effectively offset the hypothesized increased tendency of this condition to invite regret. Consistent with this interpretation, maximizers' lower offers led to obtaining more than half the available money on $20.0 \%$ of trials in the condition in which the reservation prices were shown as compared with $12.0 \%$ of trials when reservation prices were hidden. Satisficers' rates for such gains were $10.1 \%$ and $13.2 \%$, respectively.

\section{General Discussion}

The present studies provide evidence for individual differences in the orientation to seek to maximize one's outcomes in choice situations. Study 1 reported data with two new scales, a Maximization Scale and a Regret Scale, designed to measure individual differences in maximization as a goal and in sensitivity to regret. With seven independent samples, we found significant positive correlations between maximization and regret, perfectionism, and depression, and significant negative correlations between maximization and happiness, optimism, satisfaction with life, and selfesteem. We suggested that maximizers may be more concerned with relative position, and thus more inclined to engage in social comparison, than satisficers.

We explored this possible relation between maximizing and social comparison in Studies 2 and 3. In Study 2, we found that maximizers were more likely than satisficers to report engaging in social comparison, both in general and in connection with consumer decisions. We also found that maximizers were more regretful and less happy with their consumer decisions than satisficers. In Study 3, we found a tendency for maximizers to be affected by social comparison, this time in an experimental setting in which the opportunities to compare oneself with others had effects on assessments of task ability and on mood for maximizers but not for satisficers. Finally, in Study 4, we found that maximizers were less satisfied than satisficers with their results in an ultimatum bargaining game, and we obtained partial support for the hypothesis that maximizers are more sensitive to regret than satisficers.

Wieczorkowska and Burnstein (1999) recently reported evidence for an individual difference variable related to our distinction between maximizing and satisficing. They distinguished between individuals who have "point" search strategies and those who have "interval" strategies in making decisions. For the former group, the set of acceptable options is narrow, whereas for the latter it is broad. The broad "interval" strategy is adaptive when search costs are high or environmental opportunities are scarce. The "point" strategy is adaptive when search costs are low or opportunities are plentiful. Adaptive choosers are those who can adjust their search strategies in keeping with what the environment makes available. This distinction between point and interval strategies is somewhat similar to the distinction between maximizing and satisficing, but there is at least one important difference. The point strategist differs from the interval strategist in having more stringent standards of acceptability. However, those standards are clear and explicit. The maximizer, in contrast, aspires to the (more amorphous) "best." Even in an abundant environment (indeed, perhaps, especially in an abundant environment), finding the "best" will always be difficult.

Taken together, our studies suggest that although maximizers may in general achieve better objective outcomes than satisficers (as a result of their high standards and exhaustive search and decision procedures), they are likely to experience these outcomes as worse subjectively. In what follows, we explore some of the reasons why this may be so.

First, to be a maximizer is to want the best option. That, in turn, requires an exhaustive search of the possibilities. Such a search is hardly possible in any particular domain, and certainly impossible in all domains. What this may mean to a maximizer is that when practical constraints make exhaustive search impossible, there will be anticipated regret about options foregone that might have been better than the chosen option. There may also be experienced regret at the chosen option because the chosen option, though the best of all considered, was not necessarily the best in all respects. That is, other options that may have been inferior overall may have been better than the chosen option on one or more dimensions. Such regret, whether caused by experienced or imagined alternatives, is sure to reduce the satisfaction derived from one's choice. In this connection, we wonder whether maximizers would be less likely than satisficers to engage in dissonance reduction, for example, in a forced-choice paradigm.

Second, the process of adaptation will make virtually every consumption experience less satisfying than one expects it to be (e.g., Brickman \& Campbell, 1971; Frederick \& Loewenstein, 1999; Kahneman, 1999). What makes the adaptation process even worse is that people tend not to anticipate it and thus mispredict their future feelings about all sorts of experiences (Gilbert, Pinel, Wilson, Blumberg, \& Wheatley, 1998; Loewenstein \& Schkade, 1999). When the experiences are positive, failure to make allowances for adaptation will make these experiences disappointing, especially to maximizers, because their expectations will be higher than those of satisficers (see below).

A particularly relevant example of people's misprediction of future subjective states was recently reported by Gilbert and Ebert (2002), who conducted a series of studies in which participants made a choice that was either reversible or not. Though they never actually did reverse their choices, participants greatly preferred being able to do so to having their decisions be final. Tellingly, participants who had this decision-reversal option were actually less satisfied with the outcomes of their decisions than those whose decisions were irreversible. Gilbert and Ebert argued that when a decision is final, various psychological processes get recruited (e.g., dissonance reduction, rationalization) that subjectively improve the chosen alternative and denigrate the rejected one. As a result of these processes, people experience enhanced satisfaction with their decision. When people keep the option of decision reversal, however, these psychological processes are not recruited Though the research has yet to be done, we anticipate that maxi- 
mizers would be much more inclined to desire to keep options open than would satisficers.

The effects of adaptation may be worse for maximizers than satisficers for two reasons. In all likelihood, maximizers have higher standards of acceptability than satisficers, so that adaptation is more likely to be disappointing. Also, it seems likely that the decisions of maximizers entail far greater search costs than the decisions of satisficers. If we imagine that these search costs get "amortized" over the period of time in which the consequences of the decision are positive, maximizers have a bigger "debt" to amortize than satisficers.

Third, a maximizer is more likely to depend on social comparison than a satisficer. The truth of this claim seems inherent in the logic of the matter. How does a maximizer decide that he or she has attained the best possible outcome? Surely, in part, this decision is shaped by observing the outcomes of others. This logic is buttressed by the evidence from Studies 2 and 3 that indicates that maximizers do in fact engage more in social comparison, and are more affected by it, than satisficers.

Fourth, it is plausible that maximizers have higher expectations than satisficers. Given the practical constraints on search and the adaptation processes already mentioned, excessively high expectations are more likely to be met with disappointment. To the extent that subjective well-being is in significant part a function of the relation between expectations and reality, as seems likely, maximizers will often find that relation unsatisfying and unsatisfactory.

The foregoing discussion helps explain why being a maximizer may make one less happy, but what about the relation between maximizing and depression? Schwartz (2000), in discussing the choice problem, offered a speculative account of the increase in clinical depression over the course of the last century. Such an increase is surprising, because evidence suggests that having control over what happens is a key to avoiding depression (e.g., Abramson, Seligman, \& Teasdale, 1978; Peterson \& Seligman, 1984; Peterson, Maier, \& Seligman, 1993; Seligman, 1975), and it appears self-evident that adding options enhances one's potential control. The data reported in Study 1 seem to support Schwartz's speculation, at least for maximizers. But why? We believe that if there is a causal link between being a maximizer and depression, there is a key mediating factor-the presence of an overwhelming array of options.

Our argument is as follows: the theory of depression based upon the phenomenon of learned helplessness suggests that depression results from a lack of control over significant events, coupled with a particular attributional style for explanations of this lack of control (Abramson et al., 1978). Consider the kinds of attributions people might make when decisions lead to disappointing results. Who is to blame? Is it the decision maker or the world? In a world in which the options are few, it is reasonable to think that people will blame the world for disappointing results. But in a world in which the options are many, people will blame themselves. Thus, we imagine that maximizing (in triggering disappointment) and a proliferation of options (in triggering self-blame for disappointment) will interact to produce internal causal attributions for failure on the part of maximizers. The proliferation of options has two consequences related to this theory of depression. First, it raises people's standards for determining what counts as a success. From breakfast cereals to automobiles to colleges to careers, it makes sense for people to expect more when the options are plentiful than when they are scarce. Second, failure to meet those standards in a domain containing multiple options encourages one to treat failures as the result of personal shortcomings rather than situational limitations, thus encouraging a causal attribution for failure that we might call "depressogenic." So, in a world of limited options, a maximizer might be more disappointed than a satisficer with the results of his or her decisions without taking personal responsibility for the disappointing results. But in a world of limitless options, there is simply no excuse for failure.

What the above argument suggests is that it is a mistake to equate choice with a sense of control, so that the more one has of the former, the more one has of the latter. The relation between choice and perceived control may, for various reasons already discussed, be nonmonotonic (see Iyengar \& Lepper, 2000). It may be that what is often critical about control in preventing or alleviating depression is having $a$ choice, not having many choices. For example, a woman may be depressed because she feels she cannot get out of a bad relationship. Or she may be depressed because she cannot control her own depression from coming and going. The "cure" in cases like these is not an array of choices but $a$ choice.

Is maximizing always bad for people's well-being? This seems highly unlikely. Although relying on a maximizing strategy might produce adverse consequences in some contexts, it is conceivable that in others, maximizing will be an adaptive strategy. For example, an individual who responds to a health threat by searching for information, asking questions, and striving to attain the best treatment available may get better results than someone who simply selects a treatment that is sufficient. Maximizers may engage in more active coping strategies such as planful problem solving and seeking social support, whereas satisficers may cope by accepting the situation and engaging in positive reappraisal. Some of these coping responses may be more adaptive, others may be less adaptive.

Thus, it seems that there are real advantages to adopting a maximizing strategy. Presumably, not being satisfied with "good enough" spurs one on to achievements that less ambitious people will not attain, though there is as yet no evidence on this point. Perhaps in the domain of action, greater achievements by maximizers compensate for lower satisfaction with those achievements, whatever they are. But in the domain of consumption, the point of which, after all, is subjective satisfaction, this compensatory feature of maximization is much less clear.

\section{Caveats and Questions}

Throughout this discussion, we have been treating maximizers and satisficers as if there is a clear and distinct line that separates them, measurable by some instrument such as our Maximization Scale. But it is surely more accurate to say that people differ in the extent to which they are maximizers, rather than falling on one or the other side of a maximization line. That said, interesting research questions abound. There must be some variation from one domain of choice to another in the extent to which one maximizes. No one maximizes in all domains. For example, we doubt that anyone searches for the prettiest postage stamp to affix to a federal tax return. We have presented no data on the possible domain specificity of a maximization orientation. Indeed, several of the items on the Maximization Scale were written quite deliberately to 
be vague as to domain. It is possible that where on the maximizing/ satisficing continuum one falls will be a reflection not of how high one's standards of acceptability are in general, but of how many different domains of choice are dominated by a maximizing orientation. Research into the possible domain specificity of the maximization orientation, and into whether maximizers and satisficers differ in the standards they apply to decisions in general or in the number of domains in which they apply maximizing standards is in order. And beyond the matter of standards, it is important to note whether maximizers and satisficers differ in their scaling of the objective results of their decisions. It would be interesting to know whether maximizers and satisficers respond differently to measures of "objective happiness" recently pioneered by Kahneman (1999).

A second issue to be investigated is whether social comparison is not the only kind of comparison to which maximizers are more sensitive than satisficers. Michalos (1980, 1986), in his "multiple discrepancies theory," suggests that in assessing well-being, people evaluate not only what they have in relation to others, but also what they have in relation to what they expected to have, what they have had in the past, what they expect to have in the future, what they need, and what they deserve. Each of these assessments is a possible source of systematic differences between satisficers and maximizers, with maximizers consistently experiencing larger "gaps" between hopes and expectations on the one hand, and reality on the other, than satisficers do.

Another possibility worth exploring is whether maximizers and satisficers differ in what they perceive to be at stake when they make decisions. For the satisficer, all that may be at stake is the actual result of the decision-the quality of the good or the experience that is chosen. For the maximizer, the results of choices may, in addition, convey information about the self. That is, maximizers may take the outcomes of decisions as evidence about how smart, shrewd, or discerning they are as choosers. Each choice a maximizer makes may say something important about the maximizer as a person. If it is true that maximizers have so much riding on the outcomes of decisions, and if it is true, on the basis of arguments made above, that the outcomes of decisions will usually be disappointing to maximizers, it becomes unsurprising that maximizers are more depressed, more unhappy, and less optimistic than satisficers. Related to this possibility is another. If maximizers care more than satisficers about choices and their outcomes in general, they may be vulnerable not only to choices presented by the world, but to choices that they conjure up themselves. For example, the maximizing university student might imagine that there must be some way to combine a double major in finance and biology (to keep both Master of Business Administration and medical school futures open) with a minor in art, while spending a semester in Thailand and a semester in Mexico, even though all university rules indicate that this is impossible. The satisficer is less likely to be plagued by opportunities that exist only in one's imagination.

Further, future research should examine process differences between maximizers and satisficers when it comes to actual choice behavior. That is, when actually making a choice, do maximizers examine more options before selecting? Do they seek more information about alternatives? Do they desire more opportunities to reverse decisions? Do they engage in more postdecision counterfactual thinking and experience more postdecision regret? Are they more adversely affected by multiple as opposed to few choice options? The present article presents what we think are powerful data on the relation between maximization and subjective experience. It remains to be determined whether maximizers also consistently act differently than satisficers.

Finally, we should note that in discussing the relation between maximizing and dispositional happiness, we have been assuming throughout the article that the causal arrow runs from maximizing to unhappiness. Although this direction seems plausible to us, we must acknowledge that alternative conceptualizations are possible For example, people who are dispositionally unhappy are likely to be disappointed with the outcomes of many of their choices and decisions. This disappointment may be (mis)attributed to the decisions themselves, rather than their own fundamental unhappiness, leading such individuals continually to strive to make "better" choices and judgments, in an ultimately fruitless effort to enhance their happiness. Of course, such a process could also produce a cyclical relationship, whereby unhappy individuals attempt to maximize (in a misguided effort to raise their affect), leading to more unhappiness. It is critical for future research to clarify whether being maximizers makes people unhappy or being unhappy makes people maximizers. At this point, however, we simply acknowledge that just as happiness may be a matter of choice (i.e., how - and even whether — we make choices influences whether we are happy or not), choice may also be a matter of happiness.

\section{References}

Abramson, L. Y., Seligman, M. E. P., \& Teasdale, J. D. (1978). Learned helplessness in humans: Critique and reformulation. Journal of Abnormal Psychology, 87, 49-74.

Affleck, G., \& Tennen, H. (1991). Social comparison and coping with serious medical problems. In J. Suls \& T. A. Wills (Eds.), Social comparison: Contemporary theory and research (pp. 369-393). Hillsdale, NJ: Erlbaum.

Aspinwall, L. G., \& Taylor, S. E. (1993). Effects of social comparison direction, threat, and self-esteem on affect, self-evaluation, and expected success. Journal of Personality and Social Psychology, 64, 708-722.

Baron, J. (2000). Thinking and deciding (3rd ed.). New York: Cambridge University Press.

Baron, R. M., \& Kenny, D. A. (1986). The moderator-mediator variable distinction in social psychological research: Conceptual, strategic, and statistical considerations. Journal of Personality and Social Psychology, 51, 1173-1182.

Bazerman, M. H., Loewenstein, G. F., \& White, S. B. (1992). Reversals of preference in allocation decisions: Judging an alternative versus choosing among alternatives. Administrative Science Quarterly, 37, 220-240.

Bazerman, M. H., Moore, D. A., Tenbrunsel, A. E., Wade-Benzoni, K. A., \& Blount, S. (1999). Explaining how preferences change across joint versus separate evaluation. Journal of Economic Behavior and Organization, 39, 41-58

Beattie, J., Baron, J., Hershey, J. C., \& Spranca, M. D. (1994). Psychological determinants of decision attitude. Journal of Behavioral Decision Making, 7, 129-144.

Beck, A. T. (1967). Depression: Clinical, experimental, and theoretical aspects. New York: Harper \& Row.

Beck, A. T., \& Beck, R. W. (1972). Screening depressed patients in a family practice: A rapid technique. Postgraduate Medicine, 52, 81-85.

Bell, D. E. (1982). Regret in decision making under uncertainty. Operations Research, 30, 961-981. 
Bell, D. E. (1985). Putting a premium on regret. Management Science, 31, 117-120.

Blount, S., \& Bazerman, M. H. (1996). The inconsistent evaluation of absolute versus comparative payoffs in labor supply and bargaining. Journal of Economic Behavior and Organization, 30, 227-240.

Brewer, M. B., \& Weber, J. G. (1994). Self-evaluation effects of personal versus intergroup social comparison. Journal of Personality and Social Psychology, 66, 268-275.

Brickman, P., \& Campbell, D. T. (1971). Hedonic relativism and planning the good society. In M. H. Appley (Ed.), Adaptation-level theory: A symposium (pp. 287-302). New York: Academic Press.

Brown, J. D., Novick, N. J., Lord, K. A., \& Richards, J. M. (1992). When Gulliver travels: Social context, psychological closeness, and selfappraisals. Journal of Personality and Social Psychology, 5, 717-727.

Buunk, B. P., Collins, R. L., van Yperen, N. W., Taylor, W. E., \& Dakof, G. A. (1990). The affective consequences of social comparison: Either direction has its ups and downs. Journal of Personality and Social Psychology, 59, 1238-1249.

Camerer, C., \& Thaler, R. H. (1995). Ultimatums, dictators, and manners. Journal of Economic Perspectives, 2, 209-219.

Diener, E. (1984). Subjective well-being. Psychological Bulletin, 95, 542575.

Diener, E., Emmons, R. A., Larsen, R. J., \& Griffin, S. (1985). The Satisfaction With Life Scale. Journal of Personality Assessment, 49, 71-75.

Festinger, L. (1954). A theory of social comparison processes. Human Relations, 7, 114-140.

Frank, R. H. (1985). Choosing the right pond. New York: Oxford University Press.

Frank, R. H. (1999). Luxury fever. New York: Free Press.

Frederick, S., \& Loewenstein, G. (1999). Hedonic adaptation. In D. Kahneman, E. Diener, \& N. Schwarz (Eds.), Well-being: The foundations of hedonic psychology (pp. 302-329). New York: Russell Sage Foundation.

Gibbons, F. X., \& Buunk, B. P. (1999). Individual differences in social comparison: Development of a scale to measure social comparison orientation. Journal of Personality and Social Psychology, 76, 129-142.

Gibbons, F. X., \& Gerrard, M. (1989). Effects of upward and downward social comparison on mood states. Journal of Social and Clinical Psychology 8, 14-31.

Gilbert, D. T., \& Ebert, E. J. (2002). Decisions and revisions: The affective forecasting of changeable outcomes. Journal of Personality and Social Psychology, 82, 503-514.

Gilbert, D. T., Pinel, E. C., Wilson, T. D., Blumberg, S. J., \& Wheatley, T. P. (1998). Immune neglect: A source of durability bias in affective forecasting. Journal of Personality and Social Psychology, 75, 617-638.

Gillham, J., Ward, A., \& Schwartz, B. (2001). [Maximizing and depressed mood in college students and young adolescents.] Unpublished raw data.

Gilovich, T., \& Medvec, V. H. (1995). The experience of regret: What, when, and why. Psychological Review, 102, 379-395.

Guth, W., Schmittberger, R., \& Schwarze, B. (1982). An experimental analysis of ultimatum bargaining. Journal of Economic Behavior and Organization, 3, 367-388.

Hemphill, K. J., \& Lehman, D. R. (1991). Social comparisons and their affective consequences: The importance of comparison dimension and individual difference variables. Journal of Social and Clinical Psychology, 10, 372-394.

Hewitt, P. L., \& Flett, G. L. (1990). Perfectionism and depression: A multidimensional analysis. Journal of Social Behavior and Personality, 5, 423-438.

Hewitt, P. L., \& Flett, G. L. (1991). Perfectionism in the self and social contexts: Conceptualization, assessment, and association with psychopathology. Journal of Personality and Social Psychology, 60, 456-470.
Hirsch, F. (1976). Social limits to growth. Cambridge, MA: Harvard University Press.

Hsee, C. K., Blount, S., Loewenstein, G. F., \& Bazerman, M. H. (1999). Preference reversals between joint and separate evaluations of options: A review and theoretical analysis. Psychological Bulletin, 125, 576590 .

Iyengar, S. S., \& Lepper, M. R. (1999). Rethinking the value of choice: A cultural perspective on intrinsic motivation. Journal of Personality and Social Psychology, 76, 349-366.

Iyengar, S. S., \& Lepper, M. R. (2000). When choice is demotivating. Journal of Personality and Social Psychology, 79, 995-1006.

John, O. P., Donahue, E. M., \& Kentle, R. L. (1991). The "Big Five" Inventory-Versions $4 a$ and 54. Technical report (July), Institute of Personality Assessment and Research, Berkeley, CA.

Kahneman, D. (1999). Objective happiness. In D. Kahneman, E. Diener, \& N. Schwarz (Eds.), Well-being: The foundations of hedonic psychology (pp. 3-25). New York: Russell Sage Foundation.

Kahneman, D., \& Tversky, A. (1979). Prospect theory: An analysis of decisions under risk. Econometrika, 47, 263-291.

Kahneman, D., \& Tversky, A. (1984). Choices, values, and frames. American Psychologist, 39, 341-350.

Larrick, R. P., \& Boles, T. L. (1995). Avoiding regret in decisions with feedback: A negotiation example. Organizational Behavior and Human Decision Processes, 63, 87-97.

Lockwood, P., \& Kunda, Z. (1997). Superstars and me: Predicting the impact of role models on the self. Journal of Personality and Social Psychology, 73, 91-103.

Loewenstein, G., \& Schkade, D. (1999). Wouldn't it be nice? Predicting future feelings. In D. Kahneman, E. Diener, \& N. Schwarz (Eds.), Well-being: The foundations of hedonic psychology (pp. 85-108). New York: Russell Sage Foundation.

Loomes, G., \& Sugden, R. (1982). Regret theory: An alternative theory of rational choice under uncertainty. Economic Journal, 92, 805-824.

Lyubomirsky, S., \& Lepper, H. S. (1999). A measure of subjective happiness: Preliminary reliability and construct validation. Social Indicators Research, 46, 137-155.

Lyubomirsky, S., \& Ross, L. (1997). Hedonic consequences of social comparison: A contrast of happy and unhappy people. Journal of Personality and Social Psychology, 73, 1141-1157.

Lyubomirsky, S., Tucker, K. L., \& Kasri, F. (2001). Responses to hedonically-conflicting social comparisons: Comparing happy and unhappy people. European Journal of Social Psychology, 31, 1-25.

MacKinnon, D. P., \& Dwyer, J. H. (1993). Estimating mediated effects in prevention studies. Evaluation Review, 17, 144-158.

Martin, L. L., Tesser, A., \& McIntosh, W. D. (1993). Wanting but not having: The effects of unattained goals on thoughts and feelings. In D. M. Wegner \& J. W. Pennebaker (Eds.), Handbook of mental control (pp. 552-572). Englewood Cliffs, NJ: Prentice Hall.

Michalos, A. C. (1980). Satisfaction and happiness. Social Indicators Research, 8, 385-422.

Michalos, A. C. (1986). Job satisfaction, marital satisfaction, and the quality of life: A review and a preview. In F. M. Andrews (Ed.), Research on the quality of life (pp. 57-83). Ann Arbor, MI: Institute for Social Research, University of Michigan.

Morse, S., \& Gergen, K. J. (1970). Social comparison, self-consistency, and the concept of the self. Journal of Personality and Social Psychology, 16, 148-156.

Payne, J. W. (1982). Contingent decision behavior. Psychological Bulletin, 92, 382-402.

Payne, J. W., Bettman, J. R., \& Johnson, E. J. (1993). The adaptive decision maker. New York: Cambridge University Press.

Peterson, C., Maier, S. F., \& Seligman, M. E. P. (1993). Learned helplessness: A theory for the age of personal control. New York: Oxford University Press. 
Peterson, C., \& Seligman, M. E. P. (1984). Causal explanations as a risk factor for depression: Theory and evidence. Psychological Review, 91, 347-374.

Preacher, K. J., \& Leonardelli, G. J. (2001). Calculation for the Sobel test. Retrieved April 23, 2002, from http://quantrm2.psy.ohio-state.edu/kris/ sobel/sobel.htm

Ritov, I. (1996). Probability of regret: Anticipation of uncertainty resolution in choice. Organizational Behavior and Human Decision Processes, 66, 228-236.

Roese, N. J. (1997). Counterfactual thinking. Psychological Bulletin, 121, 133-148.

Rosenberg, M. (1965). Society and the adolescent self-image. Princeton, NJ: Princeton University Press.

Rosenthal, R., \& Rosnow, R. (1985). Contrast analysis. Cambridge, England: Cambridge University Press.

Rosnow, R., \& Rosenthal, R. (1989). Definition and interpretation of interaction effects. Psychological Bulletin, 105, 143-146.

Rosnow, R., \& Rosenthal, R. (1995). "Some things you learn aren't so": Cohen's paradox, Asch's paradigm, and the interpretation of interaction. Psychological Science, 6, 3-9.

Ross, L, Lepper, M. R., \& Hubbard, M. (1975). Perseverance in selfperception and social perception: Biased attributional processes in the debriefing paradigm. Journal of Personality and Social Psychology, 32, $880-892$.

Salovey, P., \& Rodin, J. (1984). Some antecedents and consequences of social-comparison jealousy. Journal of Personality and Social Psychology, 47, 780-792.

Scheier, M. F., \& Carver, C. S. (1985). Optimism, coping, and health: Assessment and implications of generalized outcome expectations. Health Psychology, 4, 219-247.

Schwartz, B. (1986). The battle for human nature: Science, morality, and modern life. New York: Norton.

Schwartz, B. (1994). The costs of living: How market freedom erodes the best things in life. New York: Norton.

Schwartz, B. (2000). Self determination: The tyranny of freedom. American Psychologist, 55, 79-88.

Seligman, M. E. P. (1975). Helplessness: On depression, development, and death. San Francisco: Freeman.

Simenson, I. (1992). The influence of anticipating regret and responsibility on purchase decisions. Journal of Consumer Research, 19, 105-118.

Simenson, I., \& Tversky, A. (1992). Choice in context: Tradeoff contrast and extremeness aversion. Journal of Marketing Research, 29, 281-295.

Simon, H. A. (1955). A behavioral model of rational choice. Quarterly Journal of Economics, 59, 99-118.

Simon, H. A. (1956). Rational choice and the structure of the environment. Psychological Review, 63, 129-138.

Simon, H. A. (1957). Models of man, social and rational: Mathematical essays on rational human behavior. New York: Wiley.

Sobel, M. E. (1982). Asymptotic intervals for indirect effects in structural equations models. In S. Leinhart (Ed.), Sociological methodology 1982 (pp. 290-312). San Francisco: Jossey-Bass.

Solnick, S. J., \& Hemenway, D. (1998). Is more always better?: A survey on positional concerns. Journal of Economic Behavior \& Organization, 37, 373-383.
Taylor, S. E. (1983). Adjustment to threatening events. American Psychologist, 38, 1161-1173.

Taylor, S. E., Buunk, B. P., \& Aspinwall, L. G. (1990). Social comparison, stress, and coping. Personality and Social Psychology Bulletin, 16, $74-89$.

Tesser, A. (1988). Toward a self-evaluation maintenance model of social behavior. In L. Berkowitz (Ed.), Advances in experimental social psychology (Vol. 21, pp. 181-222). New York: Academic Press.

Tversky, A. (1969). Intransitivity of preferences. Psychological Review, 76, 31-48.

Tversky, A., \& Kahneman, D. (1981). The framing of decisions and the psychology of choice. Science, 211, 453-458.

Tversky, A., \& Shafir, E. (1992). Choice under conflict: The dynamics of deferred decision. Psychological Science, 3, 358-361.

von Neumann, J., \& Morgenstern, O. (1944). Theory of games and economic behavior. Princeton, NJ: Princeton University Press.

Watson, D., Clark, L. A., \& Tellegen, A. (1988). Development and validation of brief measures of positive and negative affect: The PANAS scales. Journal of Personality and Social Psychology, 54, 1063-1070.

White, K., Lehman, D. R., \& Schwartz, B. (2002). [Rumination tendencies among maximizers and satisficers]. Unpublished raw data.

Wieczorkowska, G., \& Burnstein, E. (1999). Adapting to the transition from socialism to capitalism in Poland: The role of screening strategies in social change. Psychological Science, 10, 98-105.

Wills, T. A. (1981). Downward comparison principles in social psychology. Psychological Bulletin, 90, 245-271.

Wills, T. A. (1991). Similarity and self-esteem in downward comparison. In J. Suls \& T. A. Wills (Eds.), Social comparison: Contemporary theory and research (pp. 51-78). Hillsdale, NJ: Erlbaum.

Wood, J. V., \& VanderZee, K. (1997). Social comparisons among cancer patients: Under what conditions are comparisons upward and downward? In B. P. Buunk \& F. X. Gibbons (Eds.), Health, coping, and well-being (pp. 299-328). Mahwah, NJ: Erlbaum.

Zeelenberg, M. (1999). Anticipated regret, expected feedback and behavioral decision making. Journal of Behavioral Decision Making, 12, 93-106.

Zeelenberg, M., \& Beattie, J. (1997). Consequences of regret aversion 2 : Additional evidence for effects of feedback on decision making. Organizational Behavior and Human Decision Processes, 67, 63-78.

Zeelenberg, M., Beattie, J., van der Pligt, J., \& de Vries, N. K. (1996). Consequences of regret aversion: Effects of expected feedback on risky decision making. Organizational Behavior and Human Decision Processes, 65, 148-158.

Zeelenberg, M., van Dijk, W. W., van der Pligt, J., Manstead, A. S. R., van Empelen, P., \& Reinderman, D. (1998). Emotional reactions to the outcomes of decisions: The role of counterfactual thought in the experience of regret. Organizational Behavior and Human Decision Processes, 75, 117-141.

Received May 23, 2001

Revision received May 1, 2002

Accepted May 2, 2002 